\title{
The role of water vapor and convection during the Central Equatorial Pacific Experiment from observations and model simulations
}

\author{
U. Lohmann, ${ }^{1}$ E. Roeckner, ${ }^{1}$ W. D. Collins, ${ }^{2}$ A. J. Heymsfield, ${ }^{3}$ \\ G. M. McFarquhar, ${ }^{3}$ and T. P. Barnett, ${ }^{4}$
}

\begin{abstract}
Field measurements from the Central Equatorial Pacific Experiment (CEPEX) conducted from March 7 to April 5, 1993, are used to study the link between water vapor, convection, and sea surface temperature (SST) in a region of particular importance to global climate. The data are compared with results from a general circulation model (GCM). Three high-resolution simulations were carried out with slightly different initial conditions using European Centre for Medium Range Weather Forecasts (ECMWF) analyses from March 1, 1993, and forced with the observed SST as lower boundary condition. Radiosondes released between the equator and $5^{\circ} \mathrm{S}$ show a dry region east of the dateline collocated with a clear sky region observed from the Japanese Geostationary Meteorological Satellite (GMS) in the first 2 weeks of CEPEX, which both vanish in the second 2 weeks. The model is able to reproduce this change in convective activity. Moreover, a comparison of the anomalies of the relative humidity profiles grouped according to SST and infrared brightness temperature (IRBT) indicates that the GCM correctly simulates the observed behavior. The atmosphere is relatively moist when the SST is warm and low IRBTs occur at the same time, that is, when convection takes place, and dryer than on average for the opposite case. In general, however, the model is too dry in the midtroposphere and too wet in the upper troposphere. Very good agreement is found between the simulated and observed ice water content, in particular with respect to its increase with in-cloud temperature.
\end{abstract}

\section{Introduction}

Water vapor plays a pivotal role in many aspects of the Earth's climate. It is the primary greenhouse gas, absorbing radiation throughout a broad portion of the infrared spectrum. Because of the strong dependence of saturation vapor pressure on temperature, an atmospheric warming resulting from higher levels of $\mathrm{CO}_{2}$ in the atmosphere, for example, is expected to increase the greenhouse effect further by enhanced trapping of infrared radiation. Aside from its direct radiative impact, water vapor also affects the climate system through its interactions with other components of the hydrological cycle. Clouds, formed from condensation of water vapor, modify the radiative balance by reducing insolation and absorbing terrestrial thermal emission. The Earth Radiation Budget Experiment (ERBE) has shown that clouds cool the Earth-atmosphere system by $48 \mathrm{~W} / \mathrm{m}^{2}$ in the visible wavelengths and warm it by $29.8 \mathrm{~W} / \mathrm{m}^{2}$ in the infrared,

\footnotetext{
${ }^{1}$ Max Planck Institute for Meteorology, Hamburg, Germany.

${ }^{2}$ Center for Clouds, Chemistry and Climate, Scripps Institution of Oceanography, La Jolla, California.

${ }^{3}$ National Center for Atmospheric Research, Boulder, Colorado.

${ }^{4}$ Scripps Institution of Oceanography, La Jolla, Califormia.
}

Copyright 1995 by the American Geophysical Union.

Paper number 95JD02898.

0148-0227/95/95JD-02898\$05.00 referred to as albedo and greenhouse effect of clouds, respectively [Collins et al., 1994]. The link between water vapor, clouds, and temperature is a topic of considerable interest, particularly in general circulation models (GCMs). In a climate change study, Cess et al. [1990] show that the cloud radiation temperature feedback which involves large but partly compensating changes of radiative fluxes is so uncertain that even the sign of the feedback varies among the 19 participating GCMs. In most climate models, cloud cover is a function of the mean relative humidity in a grid box. Therefore a reasonable simulation of the water vapor distribution is necessary. If water vapor itself is not modeled correctly, one cannot expect to simulate the climate of the atmosphere correctly.

Chahine [1992] gives evidence that weather prediction models are sensitive to small changes in atmospheric moisture. Yet, the accuracy of humidity fields in GCMs has not received the attention it deserves. This is probably due to the paucity of humidity measurements worldwide. In tropical areas, the station density is especially low. Although microwave radiometers on satellites have provided global retrievals of precipitable water [e.g. Liu et al., 1992; Bauer and Schlïssel, 1993], studies on the validation of water vapor in GCMs or numerical weather prediction models are limited. Systematic tropical humidity errors are diagnosed by Heckley [1985] in the European Centre for Medium Range Weather Forecasts (ECMWF) humidity fore- 
casts. He finds that the atmosphere is moistened in the first few hours of the forecast, and is then dried in the middle and lower troposphere. Illari [1989] has shown that satellite derived total precipitable water provides useful information which contributes to an improvement of the ECMWF humidity analysis. Norquist and Chang [1994] diagnose systematic humidity errors in a numerical weather prediction model, independent of the initial state, compared to radiosondes and FGGE (First GARP (Global Atmospheric Research Program) Global Experiment) analyses. They find that their low-level tropical drying is linked to the convective transport, while the upper level moistening is attributable to the advective terms. Soden and Bretherton [1994] use microwave retrievals of total precipitable water and upper tropospheric relative humidity from GOES to evaluate its distribution in the National Center for Atmospheric Research Community Climate Model and in the ECMWF model. The ability of both models to simulate the primary features of total precipitable water and upper tropospheric relative humidity is highlighted. However, the ECMWF model clearly underpredicts the gradient in upper tropospheric relative humidity between the ascending and descending branch of the Hadley cell, being too dry in the tropics and too wet in the subtropics. Chen et al. [1995] follow their approach using two versions of the Hamburg GCM (ECHAM) with emphasis on longer term climate simulations. Both versions overestimate the spatial extension of upper tropospheric relative humidity over the tropical convective centers.

The aim of this study is to compare the comprehensive data set of the Central Equatorial Pacific Experiment (CEPEX) with three realizations from a high-resolution GCM driven by observed sea surface temperatures (SSTs) for the CEPEX period. CEPEX was held between March 7 and April 5, 1993, to study the link between water vapor, convection, and SST. CEPEX provided accurate intercalibrated in situ measurements of water vapor, which are more precise than operational data sets in the upper troposphere. CEPEX gives various measurements of microphysical quantities of cumulus anvils up to altitudes of $13.5 \mathrm{~km}$ in the equatorial Pacific where SSTs generally range from $300 \mathrm{~K}$ to $303 \mathrm{~K}$. Given the importance of the convection in this region and its representation of GCMs, these measurements offer a fairly unique data set for assessing how well GCMs are performing in a region of particular importance for global climate. Weaver et al. [1994] use the CEPEX data set to study the water vapor greenhouse effect and its interaction with convection. They conclude that the effect of convection can be seen in a strong rise of upper tropospheric water vapor when compared to suppressed situations elsewhere. Inamdar and $R a$ manathan [1994] compare relative humidity measurements between convective and nonconvective regimes. They find that convective regions on average are significantly more humid at every level in the troposphere than nonconvective regions. In this study we follow these approaches extending them to cumulus transport of the condensed phase as well with emphasis on model validation of the governing processes. In section 2 the relevant measurements during CEPEX are described, and in section 3 the basic features of the ECHAM4 general circulation model used in the present study together with the design of the experiments are discussed. In section 4 a general view of convection and water vapor mass is presented in terms of geographical distributions, and in section 5 the statistical relationships are analyzed. A summary of the basic results concludes this paper (section 6).

\section{Central Equatorial Pacific Experiment}

The Central Equatorial Pacific Experiment (CEPEX) was conducted from March 7 to April 5, 1993, to test Ramanathan and Collins' [1991] "thermostat" hypothesis, which proposed that highly reflective cirrus clouds act like a thermostat, shielding the ocean from radiation, thus regulating sea surface temperature. The CEPEX domain (located between $20^{\circ} \mathrm{N}$ and $20^{\circ} \mathrm{S}$ and between $140^{\circ} \mathrm{E}$ and $140^{\circ} \mathrm{W}$ ) encompasses the transition (with respect to SST) from the central equatorial Pacific to the tropical western Pacific "warm pool". The CEPEX measurements include water vapor distributions and radiative fluxes from nonconvective and convective regions. Satellite measurements were made from the Japanese Geostationary Meteorological Satellite (GMS), which is located $36,000 \mathrm{~km}$ above $\left(0,140^{\circ} \mathrm{E}\right)$ and provided excellent coverage for the CEPEX area to about $155^{\circ} \mathrm{W}$. Data were obtained hourly with a resolution of $(1.25 \mathrm{~km})^{2}$ in the visible and $8 \times 4 \mathrm{~km}^{2}$ in the infrared. The accuracy of the infrared brightness temperature is $1 \mathrm{~K}$ to $1.5 \mathrm{~K}$.

Moisture measurements include upsondes released from the $R / V$ Vickers and from island stations and dropsondes from a Learjet aircraft. The $\mathrm{R} / \mathrm{V}$ Vickers cruised during the CEPEX period from about $\left(160^{\circ} \mathrm{E}, 7^{\circ} \mathrm{S}\right)$ to about $\left(160^{\circ} \mathrm{W}\right.$, $2^{\circ} \mathrm{S}$ ) with most of the equatorial transect at $2^{\circ} \mathrm{S}$. Fifty-four soundings (including both Vaisala sondes and frostpoint hygrometer sondes) were launched 4 times daily $(00 \mathrm{Z}, 06 \mathrm{Z}$, $12 \mathrm{Z}$, and $18 \mathrm{Z}$ UT) during the course of the cruise. The upsondes are accurate to $5 \%$ in relative humidity up to approximately $250 \mathrm{hPa}$, and probably accurate within $10 \%$, up to $200 \mathrm{hPa}$ [Kley et al., 1993], which is more precise than operational data sets from routine islands or ship soundings. Also, 105 heated hygristor dropsondes were released from the Aeromet Learjet mainly between $165^{\circ} \mathrm{E}$ and $170^{\circ} \mathrm{W}$ and between the equator and $5^{\circ} \mathrm{S}$. Soundings from 18 islands, including Vaisala sondes, MicroArt sondes, and Omegasondes, located between $20^{\circ} \mathrm{N}$ and $20^{\circ} \mathrm{S}$ and between $140^{\circ} \mathrm{E}$ and $140^{\circ} \mathrm{W}$, were launched usually twice daily $(00 \mathrm{Z}$ and $12 \mathrm{Z}$ UT).

The cloud microphysical measurements were made by the Aeromet Learjet between $20^{\circ} \mathrm{S}$ and $2^{\circ} \mathrm{N}$, and between $165^{\circ} \mathrm{E}$ and $170^{\circ} \mathrm{W}$, with operations based out of Nadi, Fiji. The Learjet penetrated many different anvils in various stages of growth and produced by convection of different intensities. It flew $\mathbf{3 5}$ hours within ice clouds out of the total flight time of 108 hours during the experiment. Since the Learjet was unable to reach altitudes above $13.5 \mathrm{~km}$, data from the uppermost parts of the deepest CEPEX anvils often could not be sampled. The ice water content (IWC) measurements reported here were made with a Particle Measuring Systems 
(PMS) two-dimensional cloud (2 DC) probe, which reliably detects particles with diameters greater than 100 microns. Further details about the microphysical measurements can be found in work by G. M. McFarquhar and A. J. Heymsfield, (In-situ observations of the horizontal and vertical structure of three cirrus anvils sampled during the Central Equatorial Pacific Experiment (CEPEX), submitted to the Journal of Atmospheric Science, 1995) and A. J. Heymsfield and G. M. McFarquhar, (On the high albedos of anvil cirrus in the tropical Pacific warm pool: Microphysical interpretations from CEPEX, submitted to the Journal of Atmospheric Science, 1995). CEPEX is further described in the CEPEX Experiment Design [1993] and the CEPEX Operation Summary [1993]. Details about all of the flights are published by Aeromet in the High-Altitude Reconnaissance Platform CEPEX Data Inventory.

\section{Model Description}

The dynamics and part of the model physics of the ECHAM model have been adopted from the ECMWF model [Roeckner et al., 1992]. Prognostic variables are vorticity, divergence, temperature, (logarithm of) surface pressure, and the mass mixing ratios of water vapor and large-scale cloud water (liquid and ice phase together). The model equations are solved on 19 vertical levels in a hybrid $\mathrm{p}-\sigma$-system by using the spectral transform method with triangular truncation at wavenumber 106 (T106). Nonlinear terms and physical processes are evaluated at grid points of a "Gaussian grid" providing a nominal resolution of $\sim 1.1^{\circ} \times 1.1^{\circ}$. In contrast to ECHAM3, described by Roeckner et al. [1992], ECHAM4 uses a semi-Lagrangian technique [Rasch and Williamson, [1990] for computing the horizontal and vertical advection of positive definite quantities such as water vapor and cloud water. The radiation code is revised. In ECHAM4 it is based on a two-stream solution of the radiative transfer equation with six spectral intervals in the terrestrial infrared spectrum [Morcrette, 1989] and two in the solar part of the spectrum [Fouquart and Bonnel, 1980]. Gaseous absorption due to water vapor, $\mathrm{CO}_{2}, \mathrm{O}_{3}, \mathrm{CH}_{4}, \mathrm{~N}_{2} \mathrm{O}$, and chlorofluorocarbons (CFCs) is included as well as scattering and absorption due to prescribed aerosols and model-generated clouds. The single scattering properties of water droplets and ice crystals are derived from Mie theory, and the results are fitted to the spectral resolution of the radiation model and formulated in terms of cloud droplet and ice crystal effective radii [Rockel et al., 1991]. The cloud water content is obtained from the cloud water transport equation including sources and sinks due to condensation, evaporation and precipitation formation by coalescence of cloud droplets and sedimentation of ice crystals [Sundqvist, 1978; Roeckner et al., 1991]. Additionally, the detrained fraction from convectively generated cloud water is coupled with the stratiform cloud water equation. Phase separation in clouds is parameterized in terms of ambient temperature on the basis of empirical data [Matveev, 1984]. Subgrid scale condensation and cloud formation is taken into account by specifying appropriate thresholds of relative humidity depending on height.
Cumulus clouds are represented by a bulk model including the effects of entrainment and detrainment on the updraft and downdraft convective mass fluxes [Tiedtke, 1989]. In ECHAM4, an extension of this parameterization [Nordeng, 1994 ] is used with an adjustment closure based on the convective available potential energy (CAPE) instead of largescale moisture convergence. Organized entrainment is assumed to depend on buoyancy, and the parameterization of organized detrainment is based upon a cloud population hypothesis. The turbulent transfer of momentum, heat, water vapor, and cloud water is calculated on the basis of a higher-order closure scheme [Brinkop and Roeckner, 1995]. A new global set of land-surface parameters, including surface background albedo, surface roughness length, leaf area index, fractional vegetation cover, and forest ratio [Claussen et al., 1994] is used. A climatological comparison of the radiation budget of ECHAM4 with satellite observations from ERBE is given in Chen and Roeckner [1995] and of water vapor mass and upper tropospheric humidities in Chen et al., [1995].

For this study, three integrations with ECHAM4 are performed with initial conditions provided by ECMWF analyses of March 1, 1993. In this respect, the model is integrated as a numerical weather forecast model, which eliminates the transitory spinup behavior characteristic of climate model simulations. The model output for the entire troposphere is realistic from the first day of the simulations. The observed monthly mean SST interpolated to every model time step is used as lower boundary condition. Since the simulated time of 6 weeks is far beyond the limit of predictability, the comparison between model data and observations has been done mainly by selecting suitable statistics (cf. section 5). In order to increase the sample size, we have performed three simulations which differ only in the amount of horizontal diffusion during the first simulated day (coefficient doubled and halved, respectively). The resulting error growth is relatively small, however, so that the three realizations are statistically independent only during the second phase of the CEPEX experiment.

An alternative approach would be to apply a "nudging" technique, where the prognostic variables such as temperature and wind are "nudged" toward the observed state. The difficulty here is to find a nudging coefficient which is large enough to force the model close enough toward the observations but small enough to allow the model to develop its own physical processes. Such an experiment is currently in progress.

\section{Geographical Distributions of Water Vapor and Convection}

The SST east of the dateline increased by about $1 \mathrm{~K}$ during CEPEX. Since this has consequences for the distributions of convective activity and water vapor mass, the following analysis is split into the first half of CEPEX (March 7 to March 21, 1993) and second half (March 22 to April 5, 1993). To start with an overview of the convective activity during CEPEX, the infrared brightness temperature (IRBT) 
measured from the GMS satellite is used to diagnose convection. Because the resolution of the satellite data is much higher than that of ECHAM, the IRBT is averaged over the grid size of ECHAM. However, as pointed out by, for example, Waliser et al. [1993], Zhang [1993], and Weaver et al. [1994], it is highly disputable whether and how mean outgoing longwave radiation (OLR) or IRBT alone should be used as proxy for deep convection. The IRBTs from high cirrus not associated with any deep convective clouds are often similar to the IRBTs measured for deep convective systems. Cirrus anvils dominate convective clouds in both horizontal extension and lifetime. Therefore a low IRBT is primarily determined by the amount of high clouds, mainly cirrus, but does not directly measure deep convective clouds. On the other hand, cirrus anvils develop only in presence of deep convection and cannot last long without being refueled by new development of deep convection in the tropics [ Liou, 1986]. In general IRBT may not be a good measure of deep convective clouds, but can be used to indicate deep convective activity, especially on time scales exceeding 1 month [Zhang, 1993]. For comparison with observations, the OLR from ECHAM has been converted to IRBT using the radia- tive transfer model of Collins, Subasilar and Weaver (unpublished results, 1994).

Figure 1 shows the IRBT for the first 2 weeks of CEPEX derived from the GMS satellite data (Figure 1a) and the three model simulations (Figures 1b-1d). Large-scale descending air masses, indicated by IRBTs larger than $280 \mathrm{~K}$, prevail north of $10^{\circ} \mathrm{N}$, at the southwestern corner and between the equator and $5^{\circ} \mathrm{S}$, east of the dateline. A band of deep convective activity reaches from $\left(10^{\circ} \mathrm{N}, 160^{\circ} \mathrm{E}\right)$ to $\left(20^{\circ} \mathrm{S}, 160^{\circ} \mathrm{W}\right)$ indicated by IRBTs below $260 \mathrm{~K}$. In the three ECHAM realizations, the subtropical subsidence region north of $10^{\circ} \mathrm{N}$ is more pronounced than in the observations, as apparent from higher IRBTs. Convective activity with IRBTs below 260 $\mathrm{K}$ seems to be a permanent feature at the western edge of the CEPEX region and in the southeastern quarter but does not appear as a coherent band as shown in the satellite data. Focusing on the latitude belt between the equator and $5^{\circ} \mathrm{S}$ where most of the humidity measurements were taken, a pronounced increase in IRBT from west to east is apparent in the satellite data, especially between $160^{\circ} \mathrm{E}$ and $160^{\circ} \mathrm{W}$, but is less obvious in the model simulations. Additionally, the simulated patterns are less coherent, most likely caused by more a)

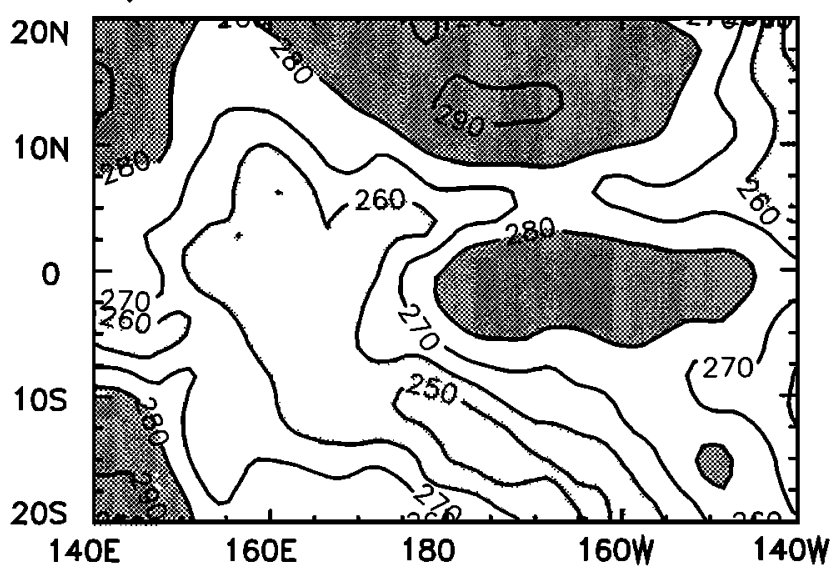

c)

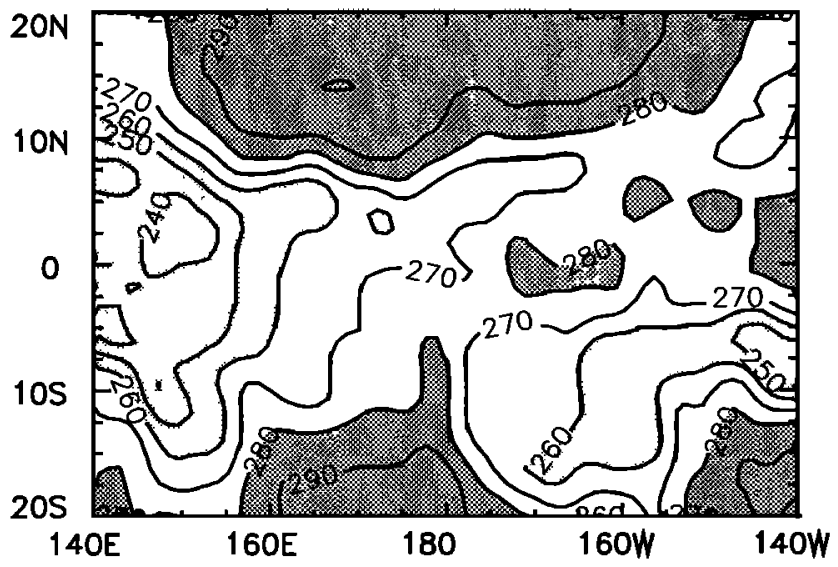

b)

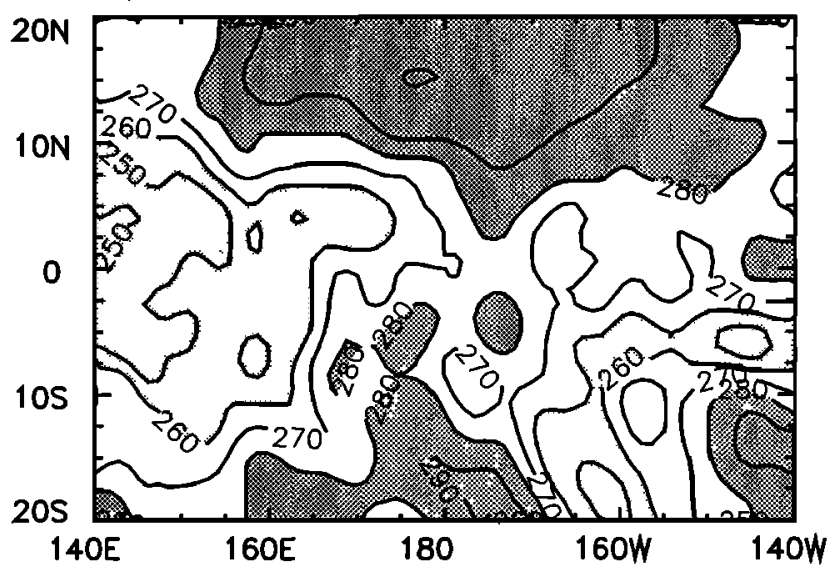

d)

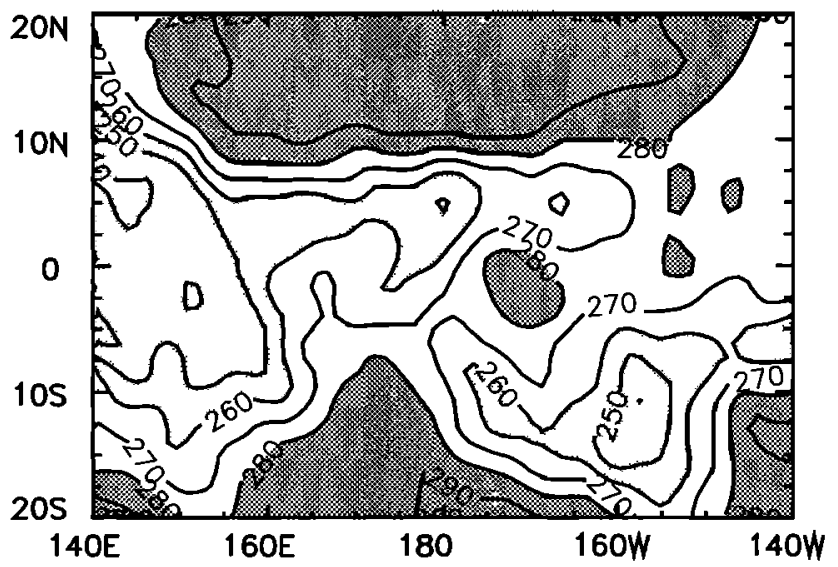

Figure 1. (a) Infrared brightness temperature (IRBT) from GMS and (b-d) the three ECHAM realizations averaged over the first 2 weeks of CEPEX (March 7 to March 21, 1993). Areas with IRBTs > $280 \mathrm{~K}$ are dark grey shaded and with IRBTs below $260 \mathrm{~K}$ are light grey shaded. Contour spacing: $10 \mathrm{~K}$. 
intense convective events, and hence stronger subsidence in adjacent areas.

The second phase of CEPEX is characterized by an increase in SST from $300.5 \mathrm{~K}$ to $301.5 \mathrm{~K}$ in the latitude belt between the equator and $5^{\circ} \mathrm{S}$. Subsequently, the area of high convective activity has shifted eastward eliminating the prevailing subsidence region in the equatorial region as indicated by decreased IRBTs in the satellite data (Figure 2a). IRBTs below $260 \mathrm{~K}$ are prevalent in two bands centered at about $5^{\circ} \mathrm{N}$ and $5^{\circ} \mathrm{S}$, respectively. The subsidence regions north of $10^{\circ} \mathrm{N}$ and in the southwestern corner have been enlarged. The three model simulations (Figures $2 \mathrm{~b}-2 \mathrm{~d}$ ) capture the change in convective activity though not as distinctly as in the satellite data. The major subsidence areas have grown and the centers of convective activity have shifted slightly to the east in the model realizations. Focusing again on the latitude band between the equator and $5^{\circ} \mathrm{S}$, the west-east IRBT gradient is diminished both in the satellite data and in the model simulations.

The most comprehensive sampling of the east-west water vapor gradient between the equator and $5^{\circ} \mathrm{S}$ is obtained through compositing the water vapor profiles from the Vickers and Learjet. Figure 3a shows the variation of the total water vapor mass with longitude from the first 2 weeks of

a)

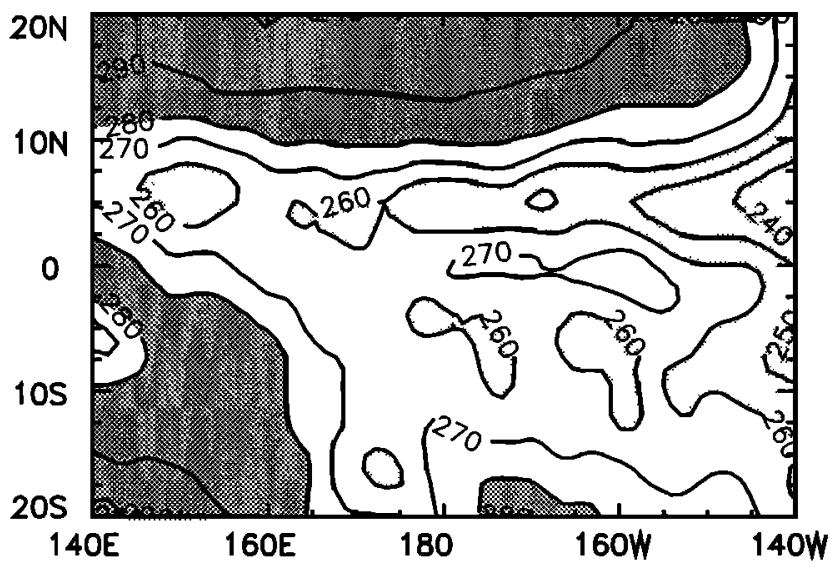

c)

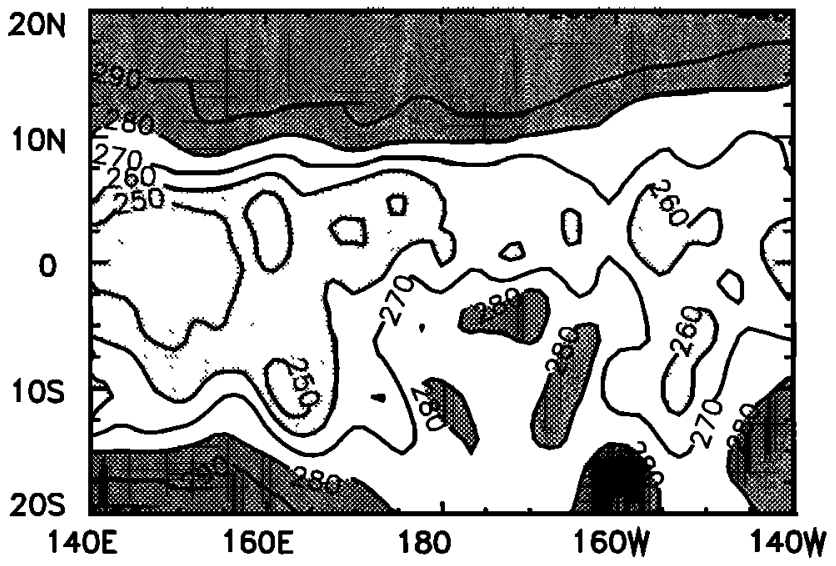

CEPEX data and the three ECHAM simulations. The data has been averaged in latitude and time. An outstanding feature is the pronounced gradient in total water vapor mass with a total of $50 \mathrm{~kg} / \mathrm{m}^{2}$ to $60 \mathrm{~kg} / \mathrm{m}^{2}$ west of the dateline and 35 $\mathrm{kg} / \mathrm{m}^{2}$ to $45 \mathrm{~kg} / \mathrm{m}^{2}$ east of it as measured from the Vaisala upsondes. Dropsondes in general show the gradient from west to east with higher values east of the dateline, however. This outlines the natural variability or range within the data both in the east-west gradient in water vapor as well as between upsondes and dropsondes. The dry region is collocated with the clear sky region detected from the GMS satellite, while the moist region coincides with low IRBTs (cf. Figure 1). This is in agreement with the findings of Inamdar and Ramanathan [1994] that convective regions on average are more humid than nonconvective regions. The SST along the track of the R/V Vickers decreases from $302.5 \mathrm{~K}$ west of the dateline to $300.2 \mathrm{~K}$ at $159^{\circ} \mathrm{W}$. Therefore this entire region can be considered as climatologically convective [Weaver et al., 1994]. The dry region in the east in the middle troposphere is caused by dry air advected from the subtropics (D. H. Kley et al., Tropospheric water vapor cross section in a zonal plane over the central equatorial Pacific, submitted to Q. J. R. Meteorol. Soc., 1995, hereinafter referred to as (D. H. Kley et al., 1995)). ECHAM is able to reproduce the dry b)

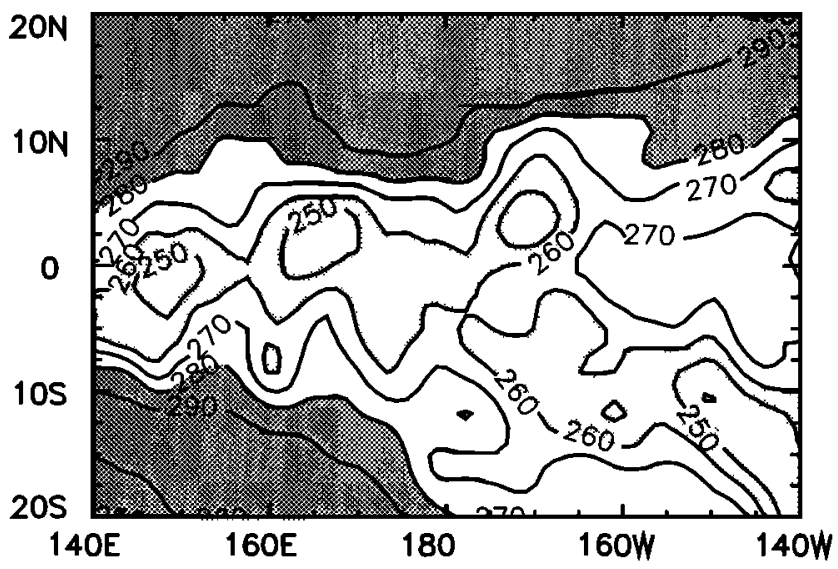

d)

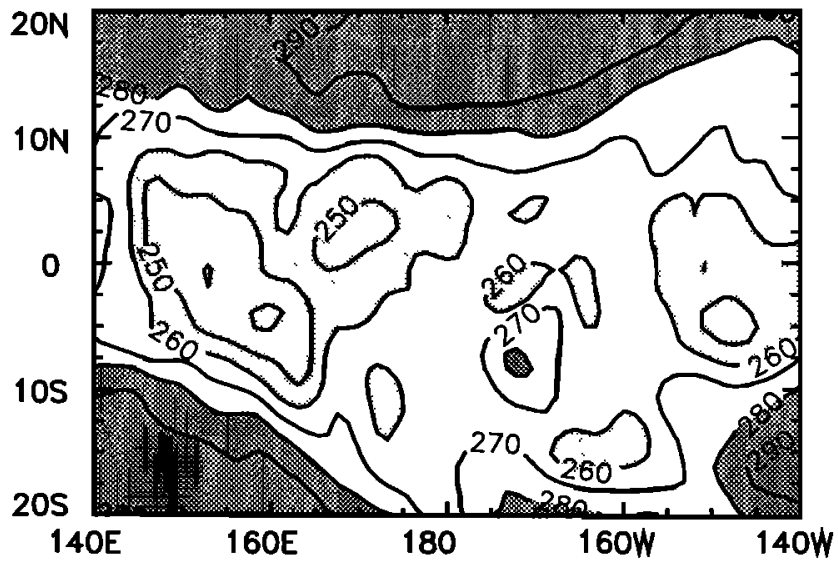

Figure 2. As Figure 1, but for the last 2 weeks (March 22 to April 5, 1993). 
a)

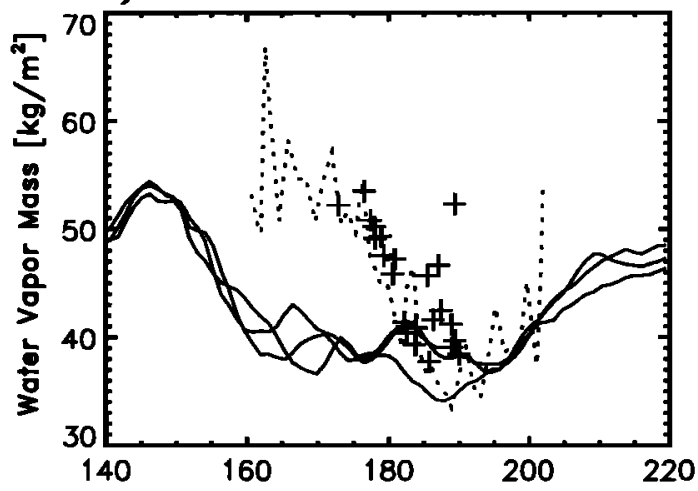

c)

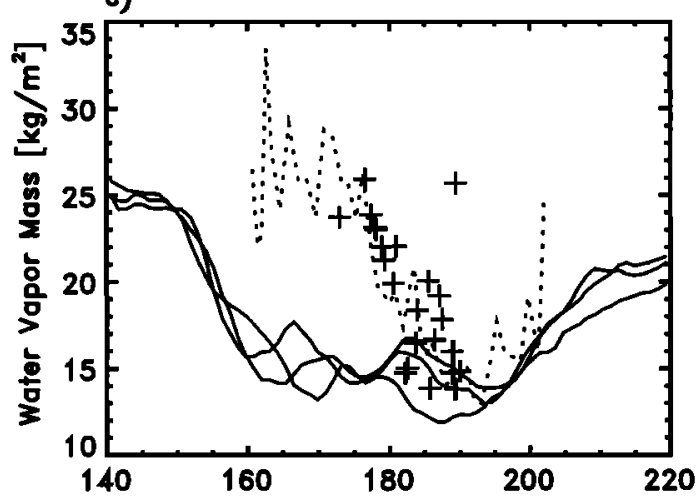

b)

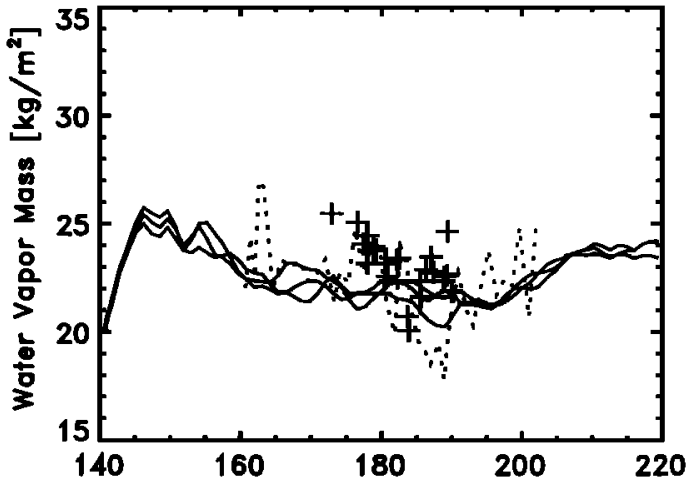

d)

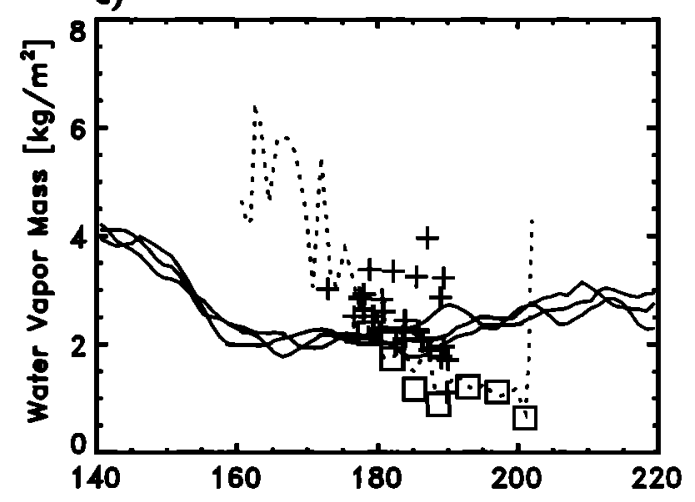

Figure 3. Vertical integrated water vapor mass measured from Vaisala upsondes situated on the R/V Vickers (dotted line), dropsondes released from the Aeromet Learjet (plus'), frostpoint hygrometers launched from Vickers (squares) and the three ECHAM4 simulations (solid lines) for the first 2 weeks of CEPEX in the latitude belt between the equator and $5^{\circ} \mathrm{S}(\mathrm{a})$ total, (b) surface $-850 \mathrm{hPa}$, (c) $850 \mathrm{hPa}-500 \mathrm{hPa}$, and (d) $500 \mathrm{hPa}$ - top of the atmosphere.

region, but stays dry also in the western part, consistent with relatively high IRBTs in that region (cf. Figure 1). Amounts of water vapor mass as high as the observed values are obtained in the GCM but shifted by about $20^{\circ}$ in longitude, with a local maximum in precipitable water between $140^{\circ} \mathrm{E}$ and $150^{\circ} \mathrm{E}$. The local maximum corresponds to a region with high convective activity. Figures $3 b-3 d$ show the water vapor mass divided up into three layers: the planetary boundary layer (surface- $850 \mathrm{hPa}$ ), the mid $(850 \mathrm{hPa}-500 \mathrm{hPa}$ ), and upper troposphere ( $500 \mathrm{hPa}$ to top of the atmosphere), respectively. The boundary layer water vapor mass changes very little from west to east, a feature obtained also by ECHAM (Figure 3b). Only small variations of water vapor below 850 $\mathrm{hPa}$ are due to changes in surface temperature [Weaver et al., 1994], that is, a constant relative humidity below $850 \mathrm{hPa}$ would result in an even smoother boundary layer water vapor mass. Above the boundary layer, a pronounced gradient from west to east is seen in both layers. Even in the upper troposphere, the water vapor content rises in convectively active regions [cf. Weaver et al., 1994]. Above $500 \mathrm{hPa}$ (Figure $3 \mathrm{~d})$ the low values of water vapor mass are additionally confirmed by measurements from frostpoint hygrometers. Between $850 \mathrm{hPa}$ and $500 \mathrm{hPa}$ (Figure $3 \mathrm{~b}$ ) the longitudinal displacement of water vapor mass is obvious in ECHAM, and in addition, the simulated vapor mass is always close to the minimum observed values. Above $500 \mathrm{hPa}$ (Figure 3d) the observed magnitude of the water vapor mass is roughly captured by the model, but the distribution is much too uniform. Nevertheless, a slight gradient from west to east with higher values in the convectively active region is suggested.

During the second half of CEPEX the convective activity, and hence high values of water vapor mass, have shifted eastward. The dropsondes, which are the only humidity measurements available in the second half of CEPEX, yield values of total water vapor mass between $49 \mathrm{~kg} / \mathrm{m}^{2}$ and 61 $\mathrm{kg} / \mathrm{m}^{2}$ within the area $163^{\circ} \mathrm{E}$ to $170^{\circ} \mathrm{W}$ (Figure 4a). Despite a large scatter of the data, a slightly reversed longitudinal gradient with higher values east of the dateline shows up. The average water vapor mass between $170^{\circ} \mathrm{E}$ and $170^{\circ} \mathrm{W}$ has increased from $45 \mathrm{~kg} / \mathrm{m}^{2}$ in the first half of CEPEX to $57 \mathrm{~kg} / \mathrm{m}^{2}$ in the second half. Although in ECHAM the water vapor mass has increased considerably as well, from $39 \mathrm{~kg} / \mathrm{m}^{2}$ to 47 $\mathrm{kg} / \mathrm{m}^{2}$, the total water vapor mass is roughly $20 \%$ lower than observed. Again, the maximum values occur at the edges of the latitude band rather than around the dateline, where the dropsondes suggest it. The boundary layer water vapor mass has become more homogeneous both in the dropsonde data and in ECHAM (Figure 4b). The largest deviation of the model from the observations occurs between $850 \mathrm{hPa}$ and $500 \mathrm{hPa}$ (Figure 4c). The dropsonde data show water vapor 
a)
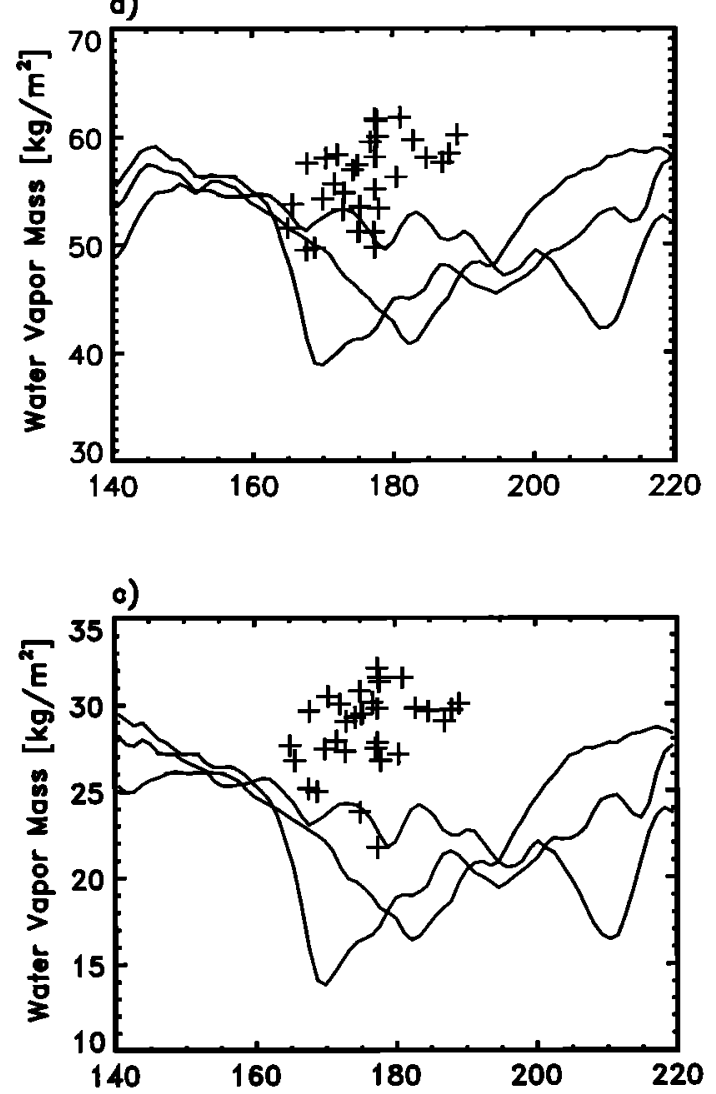

b)
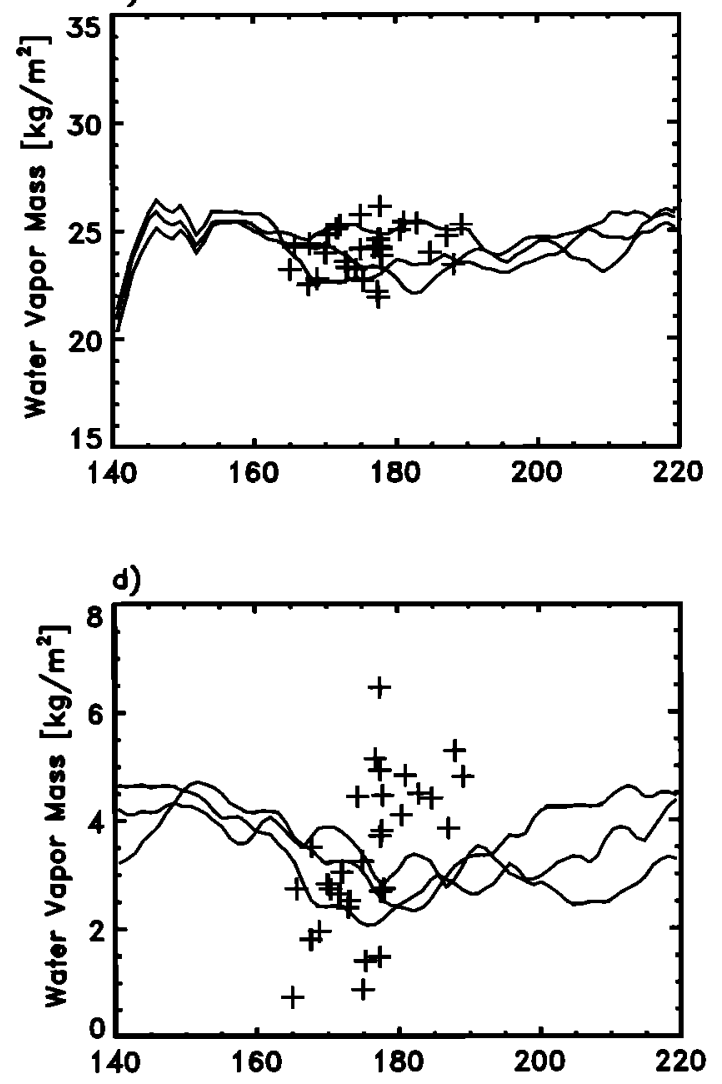

Figure 4. As Figure 3, but for the second half.

masses between $22 \mathrm{~kg} / \mathrm{m}^{2}$ and $32 \mathrm{~kg} / \mathrm{m}^{2}$, whereas ECHAM predicts only between $14 \mathrm{~kg} / \mathrm{m}^{2}$ and $29.5 \mathrm{~kg} / \mathrm{m}^{2}$ in the entire domain. Above $500 \mathrm{hPa}$, the water vapor mass of ECHAM is within the observed range of $0.7 \mathrm{~kg} / \mathrm{m}^{2}$ to $6.5 \mathrm{~kg} / \mathrm{m}^{2}$ (Figure $4 \mathrm{~d})$, but its geographical distribution is again much too uniform.

To understand the physical processes behind the simulated moisture distribution, the respective tendencies of the moisture budget are shown in Figure 5, again averaged over the latitude band between the equator and $5^{\circ} \mathrm{S}$ during the first 2 weeks of CEPEX. The net effect of deep convection (including convective transports, condensation in updrafts and evaporation of precipitation in downdrafts) is to dry the mid and high troposphere. This can be seen at both ends of the latitude band with drying rates up to $0.5 \mathrm{~g} /(\mathrm{kg} \mathrm{d})$ (Figure $5 \mathrm{a}$ ) consistent with low IRBTs in those areas (cf. Figure 1). The convective drying is compensated by the advection (Figure $5 b$ ) of moist air with moistening rates between $0.2 \mathrm{~g} /(\mathrm{kg} \mathrm{d})$ and $1 \mathrm{~g} /(\mathrm{kg} \mathrm{d})$. Although convection itself dries the atmosphere, the moistening by advection raises the relative humidity high enough for the onset of large-scale condensation. Largescale condensation (Figure 5c) adds to the drying of the troposphere by deep convection, while evaporation of cloud water and precipitation (Figure 5d) is only a small contribution to the moistening of the mid and upper troposphere compared to the advective tendencies (Figure $5 \mathrm{~b}$ ). The main effect of shallow convection (Figure 5a) is to moisten the lower tropo- sphere up to $1 \mathrm{~g} /(\mathrm{kg} \mathrm{d})$, especially pronounced in the absence of deep convection between $160^{\circ} \mathrm{E}$ and $160^{\circ} \mathrm{W}$. To summarize, in ECHAM the convective drying of the mid and upper troposphere is mainly balanced by the advection of moist air, while evaporation of precipitating ice particles plays only a minor role. ECHAM's moisture balance is therefore consistent with the "apparent moisture sink" derived from the Global Atlantic Tropical Experiment (GATE), the Marshall Islands, and other field programs [e.g., Emanuel, 1994].

\section{Relationship Between SST, Water Vapor and Convection}

Waliser and Graham [1993] (their Figures 1a-1c) showed that the frequency of organized convection rises sharply as SSTs increase from $299.5 \mathrm{~K}$ to $302 \mathrm{~K}$, reaching a maximum at $302.5 \mathrm{~K}$ and then declining at higher temperatures. The sharp increase in the frequency of organized convection with SST reflects the rapid growth in the moist static energy for air in the boundary layer. Under these conditions the typical vertical moisture and temperature structure of the atmosphere over the tropical oceans is such that saturated air parcels can ascend into the upper troposphere. Above $302.5 \mathrm{~K}$ largescale subsidence prevails, thus suppressing convection. Additionally, Waliser and Graham [1993] demonstrate that in highly convective regimes, the maximum equilibrium SST is about $302.5 \mathrm{~K}$, which is near the lower value suggested by 
a)

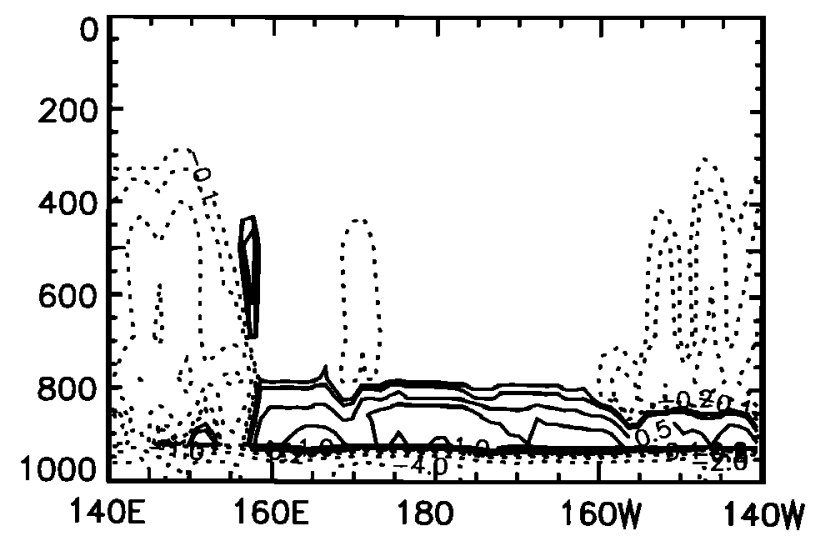

c)

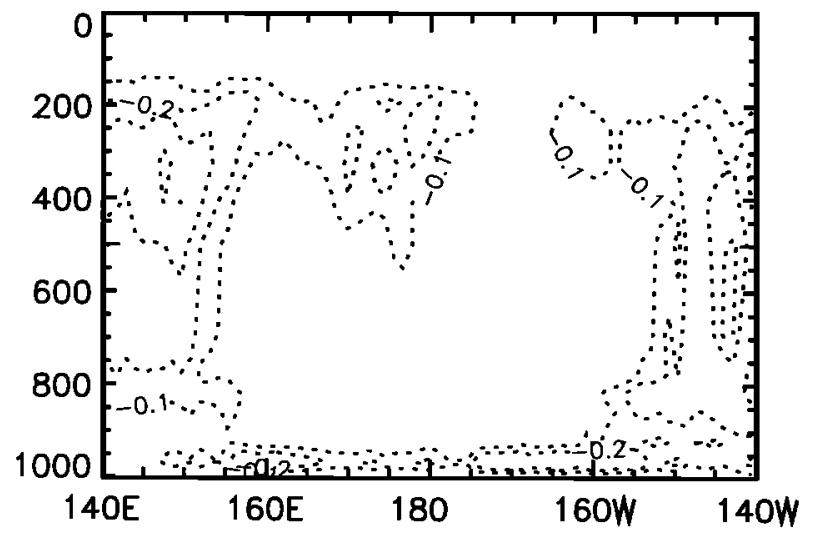

b)

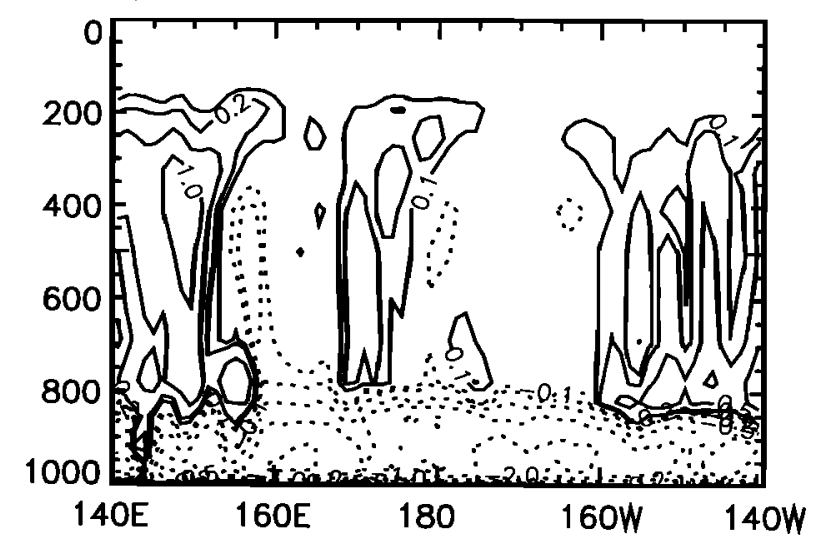

d)

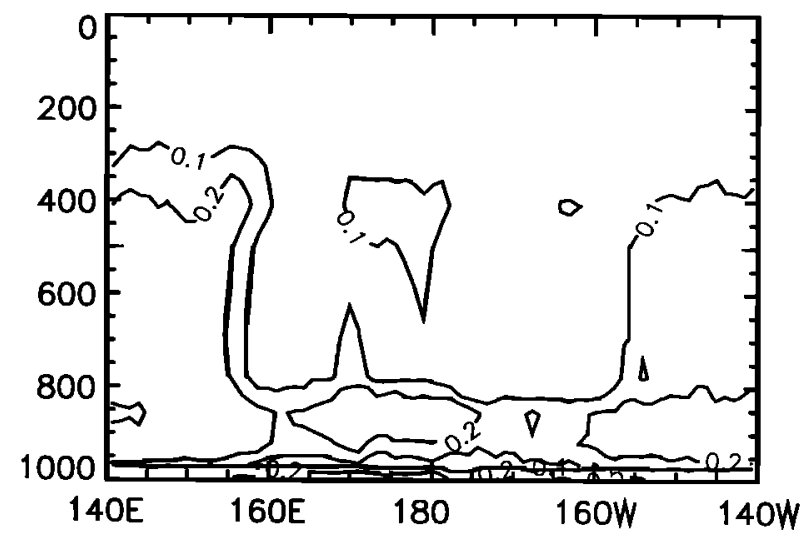

Figure 5. Tendencies of specific humidity from ECHAM in the latitude belt between the equator and $5^{\circ} \mathrm{S}$ for the first 2 weeks of CEPEX: (a) net effect of convection (deep and shallow), (b) advection, (c) large-scale condensation, and (d) evaporation of cloud water and precipitation. Contour spacing: $-8,-4,-2,-1,-0.5,-0.2,-0.1,0.1,0.2,0.5,1,2,4,8 \mathrm{~g} /(\mathrm{kg} \mathrm{d})$. Negative isolines are dashed.

Ramanathan and Collins [1991] in their thermostat hypothesis.

A similar analysis on the basis of GMS satellite data during CEPEX was done by Collins et al. [1993]. The analysis is based upon the satellite imagery between $20^{\circ} \mathrm{N}$ and $20^{\circ} \mathrm{S}, 160^{\circ} \mathrm{E}$ and $160^{\circ} \mathrm{W}$. Figure 6 a shows the probability frequency distribution of the hourly GMS IRBT versus SST, and Figure $6 \mathrm{~b}$ shows the corresponding effect in the solar spectrum, that is, the daily averaged planetary albedo at the top of the atmosphere, which is not affected by high, thin cirrus clouds. For SSTs below $298 \mathrm{~K}$, for example, the probability of IRBT to be above $280 \mathrm{~K}$ is $99 \%$, while it is only $40 \%$ at $302 \mathrm{~K}$ (Figure $6 \mathrm{a}$ ). The $0.1-$ isoline $(10 \%)$ shows the sharp increase of convective activity (decreasing IRBT), when SSTs increase from $299 \mathrm{~K}$ to $302 \mathrm{~K}$ consistent with Waliser and Graham [1993]. The decline of deep convective activity for SSTs above $303 \mathrm{~K}$ is missing because of the scarcity of data at these higher SSTs during CEPEX. Accompanying the sharp decline of IRBTs when the SST rises from $299 \mathrm{~K}$ to $302 \mathrm{~K}$, the albedo increases (Figure 6b), indicating thick high clouds associated with the onset of deep convection. At $298 \mathrm{~K}$ the probability of the albedo to be lower than
$20 \%$ is $95 \%$, whereas at $302 \mathrm{~K}$ it is only $40 \%$. At $302.3 \mathrm{~K}$ the probability for higher albedos decreases followed by another sharp increase at $302.8 \mathrm{~K}$. Because of the paucity of data with high SSTs, it is difficult to determine whether this increase is a statistical artifact or a real feature.

The same analysis applied to ECHAM including data from the three realizations within the same region $\left(20^{\circ} \mathrm{N}\right.$ to $20^{\circ} \mathrm{S}$, $160^{\circ} \mathrm{E}$ to $160^{\circ} \mathrm{W}$ ) is shown in Figures $7 \mathrm{a}$ and $7 \mathrm{~b}$. The overall behavior of probability of occurrence of IRBTs with SST bears considerable resemblance with the GMS analyses, for example, the 0.1-isoline has the same slope as observed. The 0.2 to 0.6 -isolines in ECHAM have a steeper slope than observed between $301 \mathrm{~K}$ and $302 \mathrm{~K}$ and level off for SSTs above $302 \mathrm{~K}$. The same isolines in the satellite data decrease more steadily except for a secondary maximum at $302.8 \mathrm{~K}$. Consequently, as could be seen from the geographical comparison of IRBTs (cf. Figures 1a and 2a), high IRBTs at relatively cold SSTs and low IRBTs at relatively high SSTs occur more frequently in ECHAM than in the GMS data. In the shortwave spectrum, the sharp rise in probability for higher albedos that occur when SSTs rise from $299 \mathrm{~K}$ to $302 \mathrm{~K}$ is reproduced in ECHAM (Figure 7b). It should be expected that the 

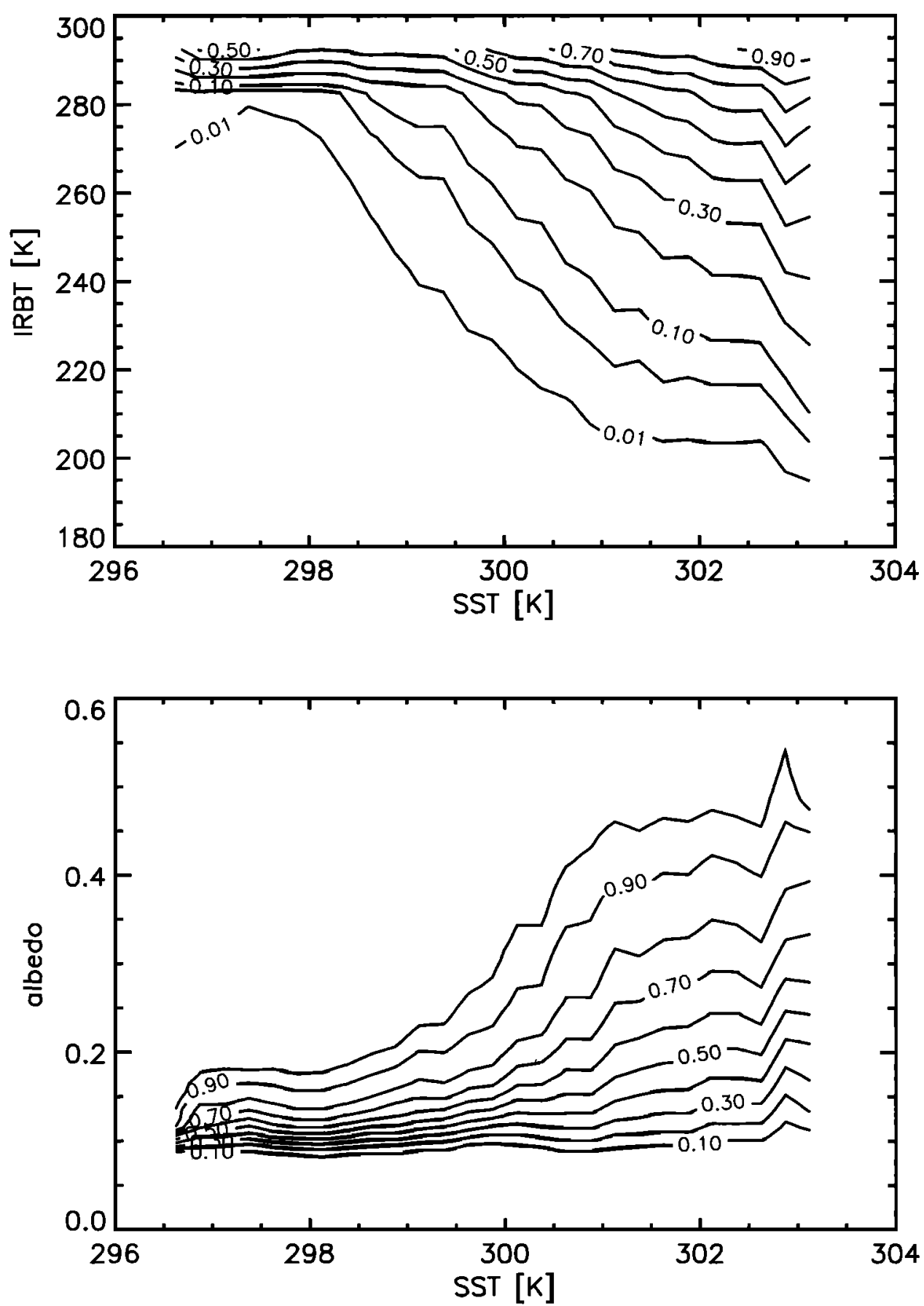

Figure 6. (top) Probability frequency distribution of hourly GMS IRBTs versus SST for all data points within $20^{\circ} \mathrm{N}-20^{\circ} \mathrm{S}$, $160^{\circ} \mathrm{E}-160^{\circ} \mathrm{W}$. Contour spacing: $0.01,0.05,0.1,0.2,0.3,0.4,0.5,0.6,0.7,0.8,0.9$. (bottom) Probability frequency distribution of daily mean GMS albedo versus SST. Contour spacing: $0.1,0.2,0.3,0.4,0.5,0.6,0.7,0.8,0.9,0.95$

median albedo value, which is close to $50 \%$, increases with SST. This feature hardly shows up in the GMS data but is obtained by the GCM. The decline of probability of higher albedo values at $302.3 \mathrm{~K}$ and rise at $302.8 \mathrm{~K}$ is reflected in ECHAM. Note that ECHAM is driven by monthly mean SST interpolated to every time step. Accordingly, the SSTs input into the model do not necessarily span the range of observed SSTs. As a result, the statistics near the maximum and minimum SSTs may be affected by inadequate sampling, and the results should be interpreted with caution.
As shown above, both satellite and model data indicate a close correspondence between SST and level of convective activity. We have also used CEPEX data to investigate whether the model is able to simulate the observed relationship between SST, convection and relative humidity in the middle and upper troposphere.

D. H. Kley et al. (1995) have analyzed observed vertical relative humidity profiles (always assuming saturation with respect to water) obtained from Vaisala upsondes released from the Vickers and dropsondes released from the Learjet 

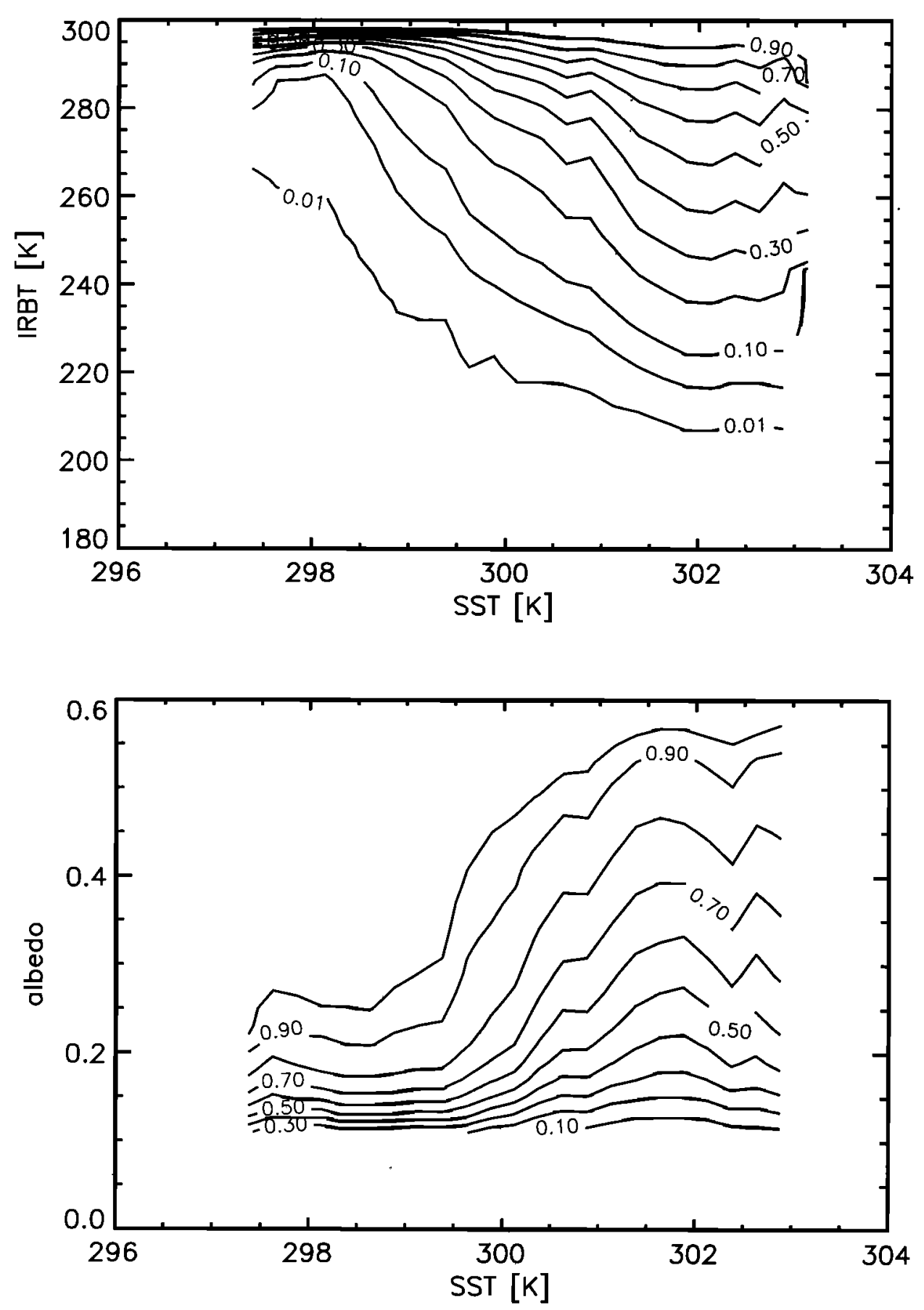

Figure 7. As Figure 6, but for all data of the three ECHAM4 realizations within the same region.

during CEPEX. These profiles have been grouped according to SST (below/above $301.5 \mathrm{~K}$ ) and IRBT (below/above $250 \mathrm{~K}$ ), respectively. Long-term studies of tropical systems indicate that convective activity increases rapidly with SST starting at approximately $301.5 \mathrm{~K}$ [cf. Graham and Barnett, 1987; Waliser and Graham, 1993]. This threshold SST is also evident in the probability distribution function of IRBT for the CEPEX period (cf. Figure 6). Above $301.5 \mathrm{~K}$ at least $50 \%$ of all cases have IRBTs below $280 \mathrm{~K}$ and albedos above $20 \%$. The IRBT threshold of $250 \mathrm{~K}$ represents a dividing line between two distinct populations of samples during CEPEX
[Weaver et al., 1994]. Figures 8a-8d show the relative humidity profiles for those four cases interpolated to a vertical resolution of $20 \mathrm{hPa}$ bins. The dotted lines on both sides of the thick solid one indicate the standard deviation, while the thin straight line is a somewhat arbitrary linear decrease of relative humidity with height as reference line. In the case of high SST and low IRBT (Figure 8a), the observed relative humidity profile stays moist up to $300 \mathrm{hPa}$, starting with $85 \%$ near the surface and slightly decreasing to $70 \%$ at 300 hPa. Above $300 \mathrm{hPa}$, it drops rapidly to $50 \%$ at $200 \mathrm{hPa}$. In the opposite case, that is, low SST and clear sky conditions 

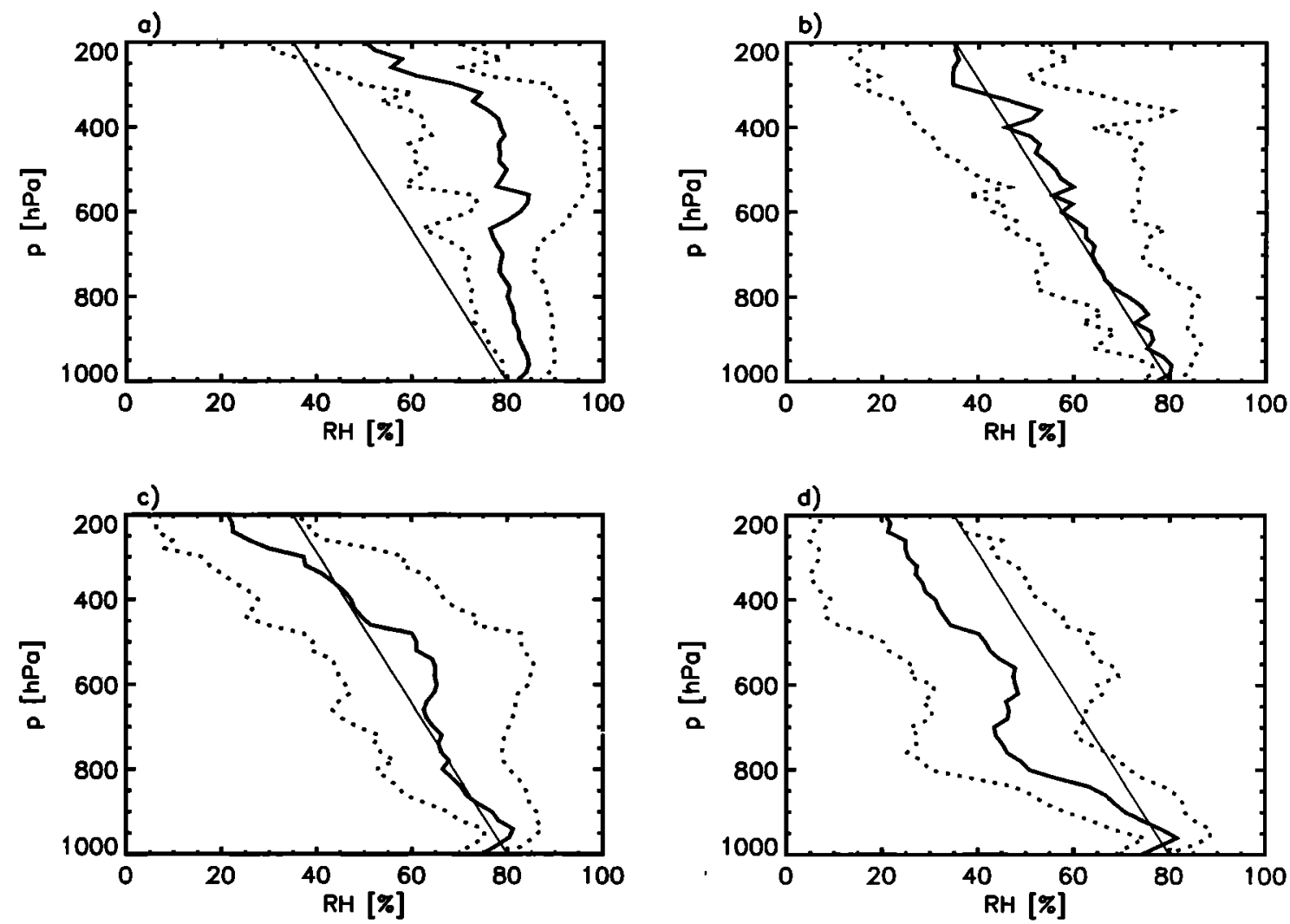

Figure 8. Vertical profiles of relative humidity (always assuming saturation with respect to water) from Vaisala upsondes and dropsondes grouped according to their SST and infrared brightness temperature (IRBT). The dotted lines at both sides of the thick solid line indicate the standard deviation, the thin solid line is a reference line: (a) SST $>301.5 \mathrm{~K}$, IRBT < 250 K, (b) SST > 301.5 K, IRBT > 250 K, (c) SST < 301.5 K, IRBT < $250 \mathrm{~K}$ and (d) SST < 301.5 K, IRBT > 250 K.

(Figure 8d), the relative humidity declines sharply above the near surface inversion. Between $700 \mathrm{hPa}$ and $550 \mathrm{hPa}$ a second inversion shows up, above which the relative humidity drops to $20 \%$ at $200 \mathrm{hPa}$. Both intermediate cases (Figures $8 \mathrm{~b}$ and $8 \mathrm{c}$ ) show a relatively steady, almost linear decrease of relative humidity with height. The standard deviation in all cases increases with height, showing largest variability between $600 \mathrm{hPa}$ and $300 \mathrm{hPa}$.

The same analysis has been applied to the ECHAM data between the equator and $5^{\circ} \mathrm{S}$ and between $160^{\circ} \mathrm{E}$ and $160^{\circ} \mathrm{W}$ (Figures 9a-9d). Obviously, ECHAM has a dry systematic error in the lower troposphere and a moist one in the upper troposphere, which is present in all four composites. The relative humidities do not decrease linearly with height as the observations suggest, but decline sharply above the near surface inversion to turn into another inversion at or below 400 $\mathrm{hPa}$. However, the inversion in relative humidity near the surface is captured in ECHAM. Figures 10a-10d and 11a$11 \mathrm{~d}$ show the anomalies of relative humidity with respect to the whole sample for those four cases of the observations and the GCM, respectively. In the warm and convective case (Figure 10a), the positive relative anomaly increases with height yielding a $30 \%$ moister atmosphere above $450 \mathrm{hPa}$. The atmosphere is up to $20 \%$ drier in the opposite case between $800 \mathrm{hPa}$ and $400 \mathrm{hPa}$ (Figure 10d) while the two intermediate cases (Figures $10 \mathrm{~b}$ and $10 \mathrm{c}$ ) show only slight devi- ations from the mean. Figures 11a-11d show that ECHAM is able to reproduce the sign of the anomalies with respect to SST and IRBT, although the magnitude of anomalies differ. The anomaly for the warm and moist case is not as pronounced as in the observations (Figure 11a versus 10a), but the vertical structure reflects the observed one. The same holds for the dry and cold case (Figure 11d versus 10d), whereas the deviations from the mean are larger in the intermediate cases in ECHAM (Figures $11 \mathrm{~b}$ and $11 \mathrm{c}$ versus $10 \mathrm{~b}$ and 10c).

The mean relative humidity profiles of the radiosondes and of the three ECHAM realizations are shown in Figure 12 together with the standard deviation from the observations. The upsondes released from the Vickers are likely up to $10 \%$ too dry in the boundary layer (S. Sherwood, personal communication, 1994). The decline of relative humidity in the boundary layer is more pronounced in the model and it is generally too dry up to about $300 \mathrm{hPa}$. Zhang et $a l$. [1994] observed the same feature by comparing the previous ECHAM version with upsondes launched from Vickers. Figure 13 shows the average relative humidity profiles from all radiosondes launched from all island stations (solid line) within the entire CEPEX domain and time and the same mean from the three ECHAM simulations. The island soundings show a decrease of relative humidity up to $700 \mathrm{hPa}$ with a slight inversion above and a modest monotonic de- 

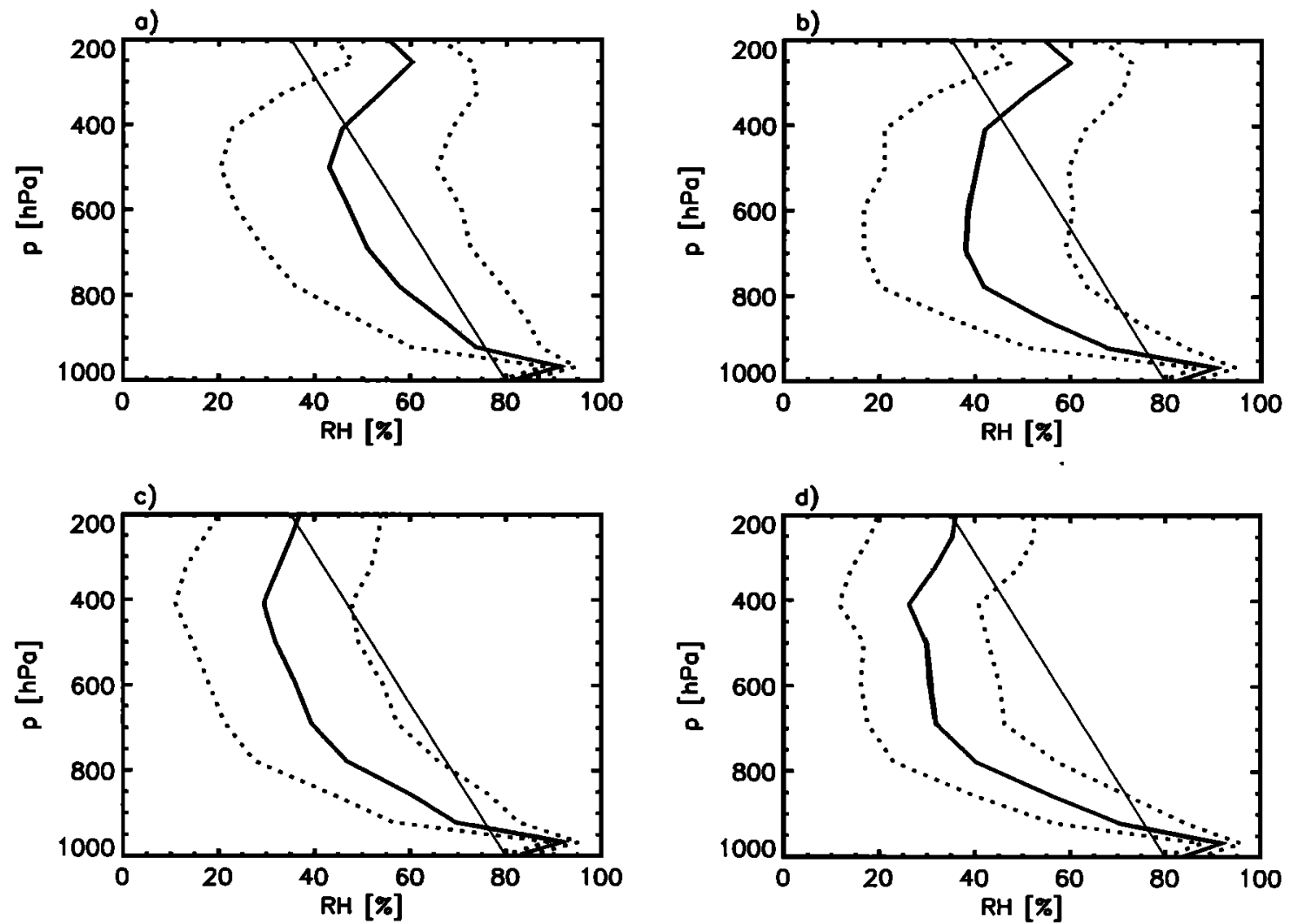

Figure 9. As Figure 8, but for all data of the three ECHAM4 realizations between the equator and $5^{\circ} \mathrm{S}$ and between $160^{\circ} \mathrm{E}$ and $160^{\circ} \mathrm{W}$.
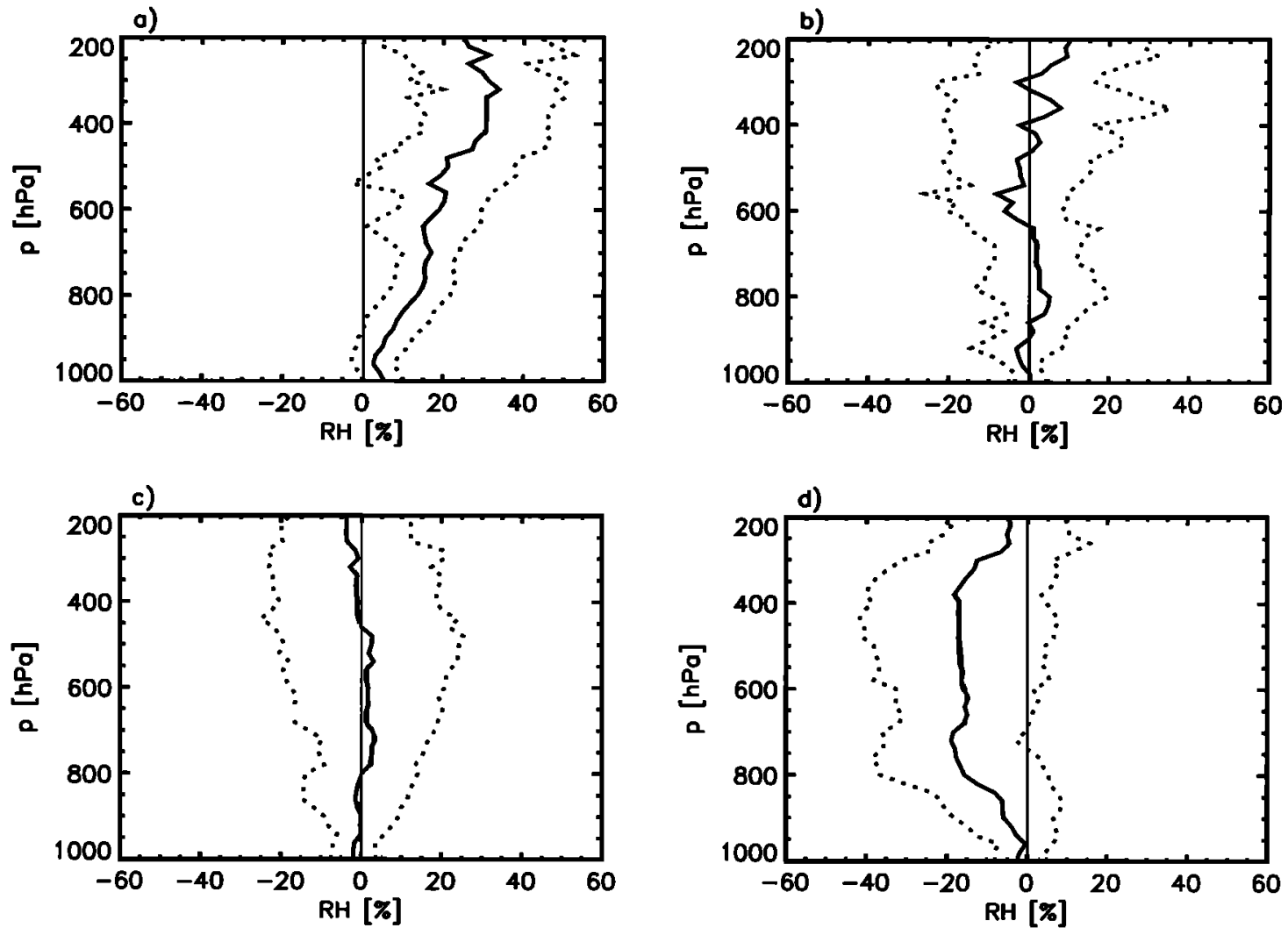

Figure 10. As Figure 8, but as anomalies from the mean. 

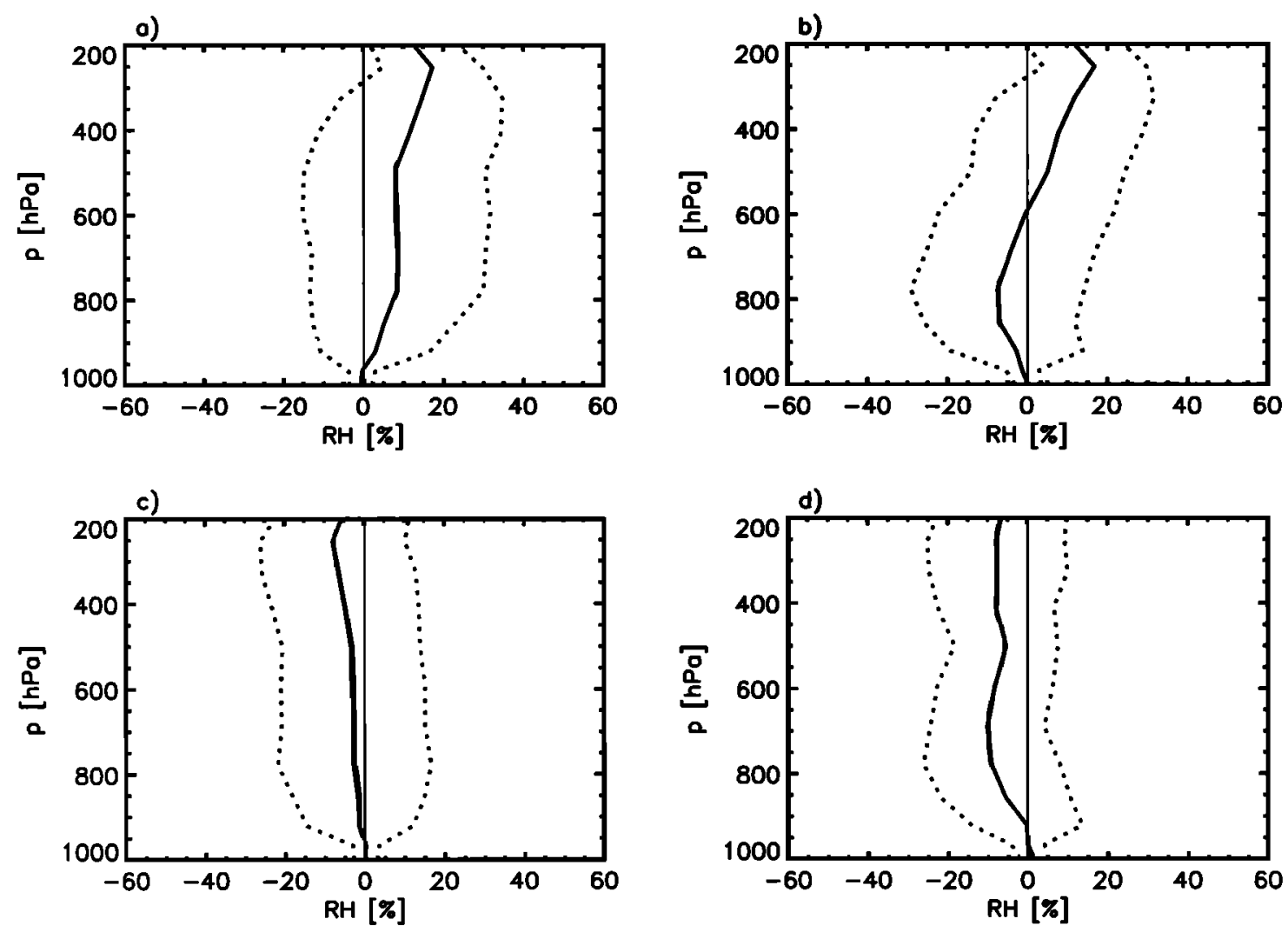

Figure 11. As Figure 9, but as anomalies from the mean.

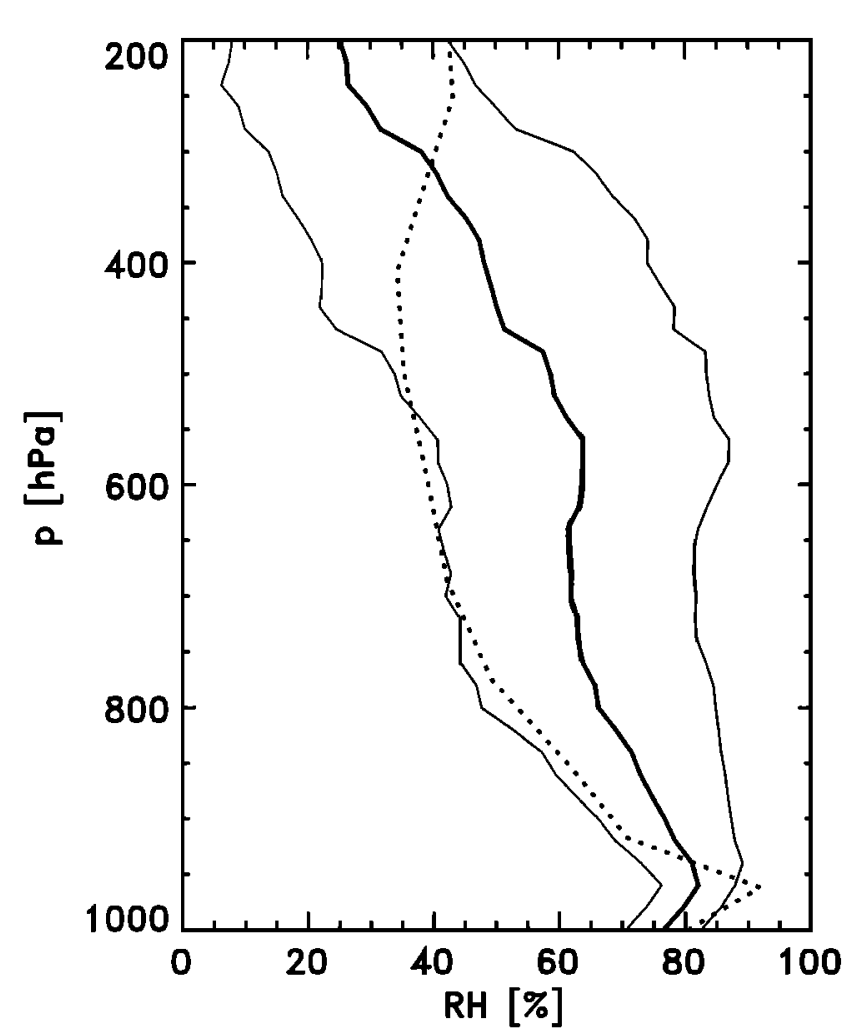

Figure 12. Mean relative humidity profiles averaged over all the radiosonde data (thick solid line) together with their standard deviation (thin solid lines) and the respective ECHAM data (dotted line).

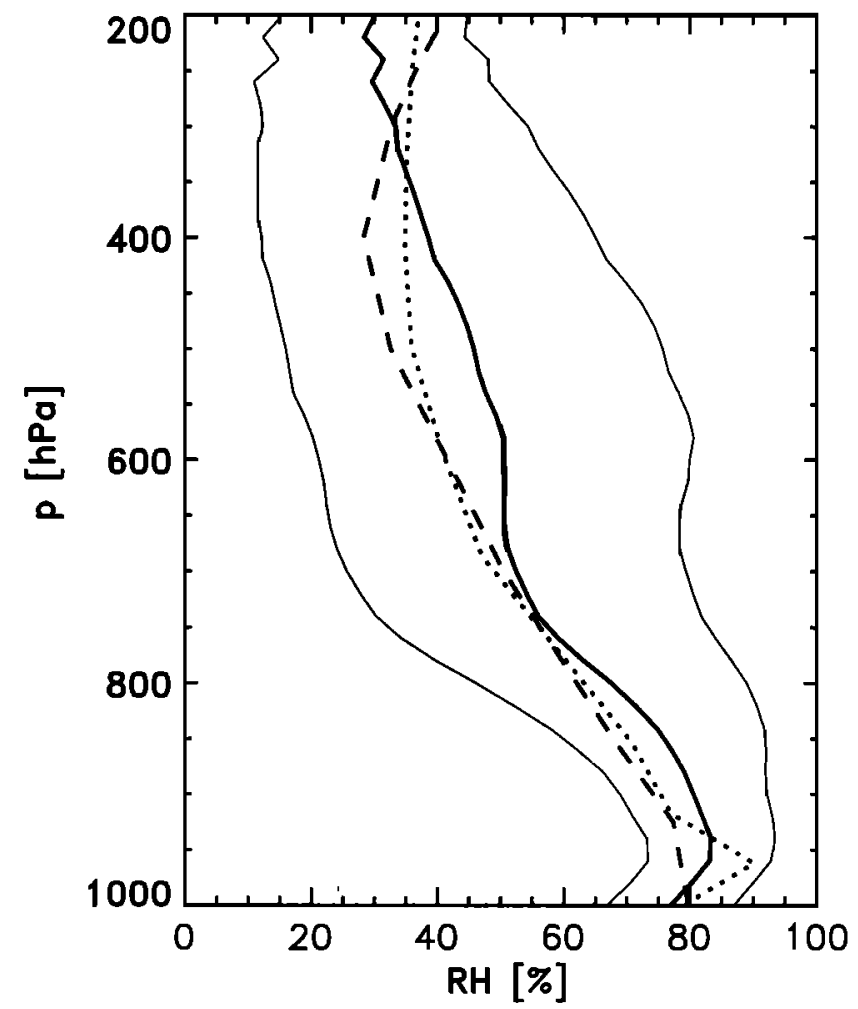

Figure 13. Mean relative humidity profiles averaged over the whole CEPEX domain and time from Island soundings (thick solid line) plus standard deviation (thin solid lines) and the respective ECMWF analyses (dashed line) and ECHAM data (dotted line). 
crease above $600 \mathrm{hPa}$. In ECHAM the mean relative humidity decreases up to $500 \mathrm{hPa}$ and stays almost constant aloft. When compared to the more convective region covered by the radiosondes released from the Vickers and Learjet (cf. Figure 12), only the magnitude of its bias is reduced. The standard deviation of all island stations radiosondes in the midtroposphere is larger than that of the Vickers and Learjet radiosondes because some islands are located at the relative dry edge of CEPEX, while others are situated in convectively active areas. In addition, an average profile from 6 . hourly ECMWF analyses with $0.5^{\circ} \times 0.5^{\circ}$ spatial resolution is shown as dashed line. Similar to ECHAM, the ECMWF analyses are too dry in the midtroposphere and too moist above $300 \mathrm{hPa}$.

The dry bias in relative humidity in the midtroposphere could be caused either by an underestimate of specific humidity, an overestimate of atmospheric temperature, or by a combination of both. On the other hand, a correct relative humidity profile could be obtained by compensating errors in temperature and specific humidity. To illustrate this point further, Figure 14 also shows the relative humidity profile calculated using the observed temperature and the simulated specific humidity (dashed line). In the midtroposphere the modeled temperature is between $0.5 \mathrm{~K}$ and $1 \mathrm{~K}$ too high (not shown), and thus the relative humidity calculated with the observed temperature is increased up to $2.5 \%$ higher. Above $300 \mathrm{hPa}$, however, the higher modeled temperature partly compensates the overestimate of specific humidity so that the original profile of relative humidity from the model is closer to the observed one. As expected, calculating the relative humidity profile with the observed specific humidity (dasheddotted line) yields a relative humidity profile which is close to the observed one. The curves diverge at higher levels because the error in temperature increases with height.

Another possibility is that the errors in relative humidity only appear in the CEPEX time frame and are not climatological. Therefore we compared the relative humidity profile averaged over the entire CEPEX domain and time with monthly mean relative humidities of each simulated March from a 15-year integration with ECHAM4-T42. This experiment was forced with the observed SST and sea ice for the period 1979-1993 from the atmospheric model intercomparison project (AMIP) data set [Gates, 1992]. The different modeled relative humidity profiles are more similar to each other (indepedent of the horizontal resolution) than to the observations. Therefore the possibility that the error in relative humidity is merely a sampling problem, or specific for the CEPEX time frame can be excluded.

The excessive moisture in the upper troposphere could be related to errors in the general circulation as Norquist and Chang [1994] and Chen et al. [1995] concluded. The zonal mean wind and velocity potential from ECMWF analyses and ECHAM are shown in Figures 15a-15d. The fields are averaged over the first 2 weeks of CEPEX and over the latitude belt between the equator and $5^{\circ} \mathrm{S}$. The analyzed zonal mean wind has a quadrupole structure, with low-level westerlies and upper level easterlies west of the dateline and winds of opposite sign east of the dateline (Figure 15a). The

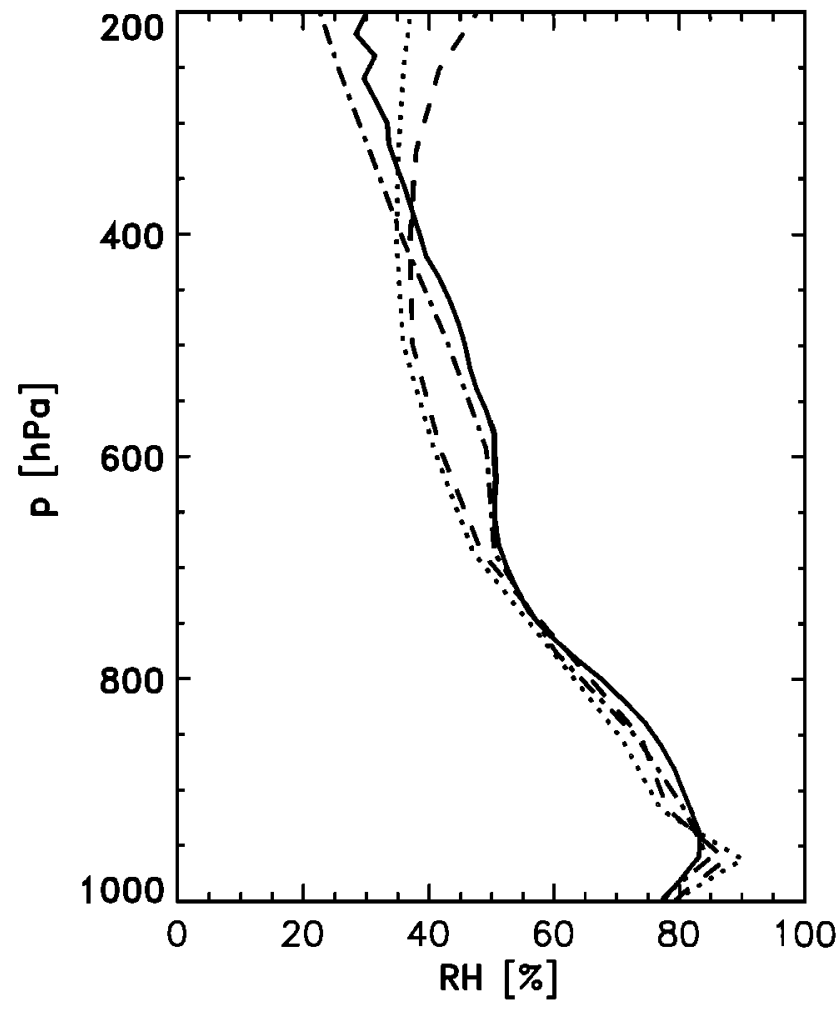

Figure 14. As Figure 13, but additionally including the modeled relative humidity profile calculated with the observed temperature (dashed line) and the modeled relative humidity profile calculated with the observed absolute humidity (dashed-dotted line).

zonal mean wind from ECHAM (Figure 15b) has the same structure, but the maxima are shifted to the edges of the domain and the low-level westerlies are too weak. The velocity potential from ECHAM closely resembles the one from ECMWF, as shown in Figures 15c-15d. The intensity of the low-level convergence and upper level divergence within this latitude belt, and hence the vertical advection of water vapor, are reproduced in the model simulations. To conclude, the biases in relative humidity are similar to those of specific humidity. They are neither related to the general circulation during CEPEX nor do they appear only in the CEPEX time frame. Additional possible error sources are discussed below.

In the tropics, most cirrus anvils are produced from the outflow of convective cores. Therefore a comparison of the simulated and observed ice water content (IWC) in cirrus anvils will indicate if the cumulus transport of the condensed phase together with the appropriate cloud microphysical processes are achieved in the model. Figure 16 shows the average IWC mainly from anvils connected to cumulus clouds versus in-cloud temperature in $5 \mathrm{~K}$ temperature bins for all Learjet data (stars) together with vertical bars indicating the $25 \%$ and $75 \%$ quartiles. The observed average IWC covers 2 orders of magnitude, increasing from about $0.0015 \mathrm{~g} / \mathrm{m}^{3}$ at $205.5 \mathrm{~K}$ to $0.2 \mathrm{~g} / \mathrm{m}^{3}$ at $260.5 \mathrm{~K}$. Above $253 \mathrm{~K}$, the Learjet data could be affected by liquid water and should be regarded with caution. The average IWC is dominated by a few cases 
a)

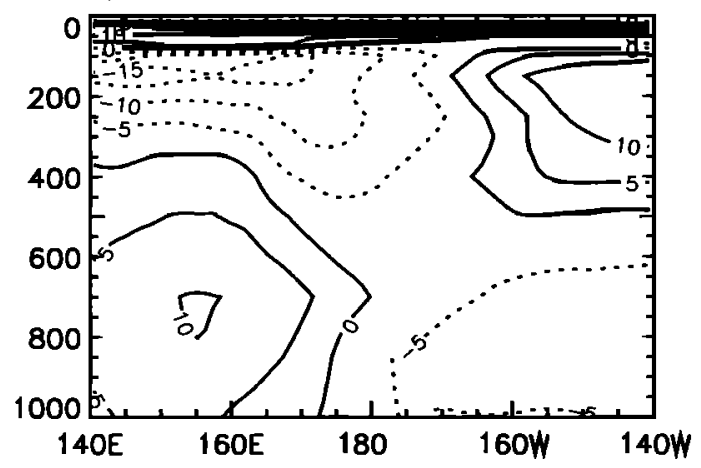

c)

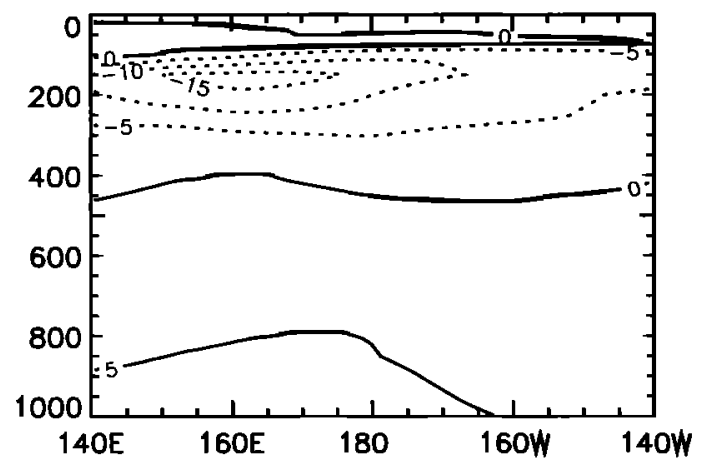

b)

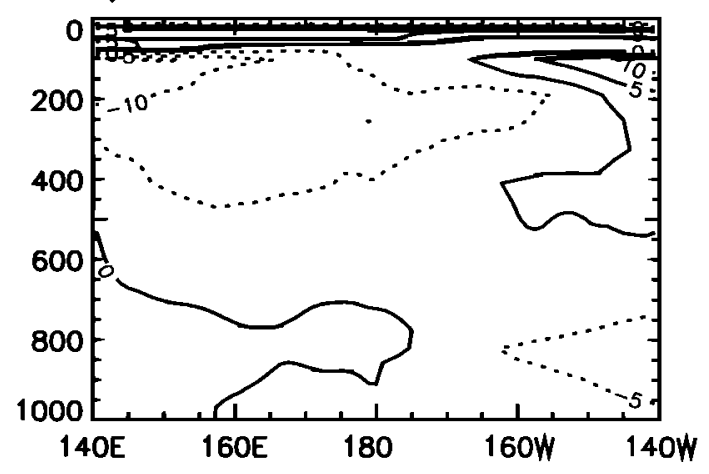

d)

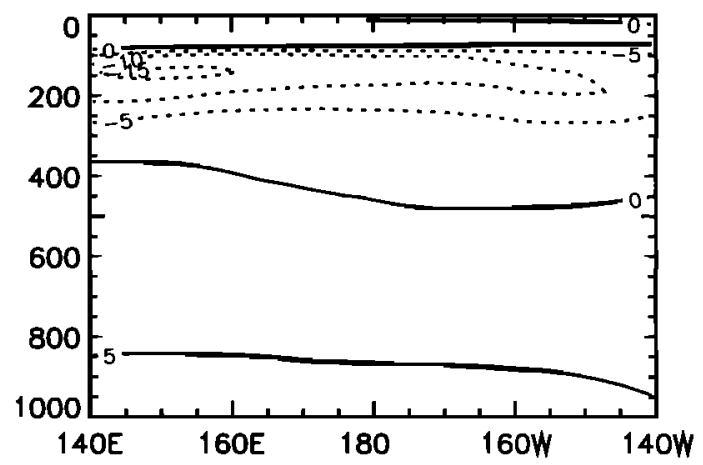

Figure 15. (a) Zonal mean wind from ECMWF and (b) the three ECHAM realizations and (c) velocity potential from ECMWF and (d) ECHAM in the latitude belt between the equator and $5^{\circ} \mathrm{S}$ for the first 2 weeks of CEPEX. Contour spacing: $5 \mathrm{~m} / \mathrm{s}$ (wind) and $5 \mathrm{~km}^{2} / \mathrm{s}$ (velocity potential). Negative isolines are dashed.

with large IWCs, because the IWC in each temperature bin is positively skewed. Therefore the average IWC can exceed the $75 \%$ percentile value (Figure 16). A relationship of average IWC versus temperature derived from another tropical dataset at Kwajalein [Heymsfield, 1993] is indicated as dotted line. Although the slope is similar, the absolute values are lower when compared with CEPEX measurements. The average IWC from all three ECHAM realizations, which is mostly contained in cumulus anvils, reproduce the observed relationship between IWC and temperature. Owing to the coarser resolution in the model (one grid cell in the tropics is about $125 \mathrm{~km} \times 125 \mathrm{~km}$ ), extreme values of IWC will not appear in the results. The $5 \%$ and $95 \%$ values in the model cover at most 2 orders of magnitude, whereas they cover 2 to 5 orders of magnitude in the observations. Hence the variability within each temperature bin is underestimated in the model (not shown).

\section{Summary and Conclusions}

In this paper the comprehensive data set from the Central Equatorial Pacific Experiment (CEPEX) has been used to study the link between water vapor, convection and SST in comparison with three realizations obtained from a highresolution GCM.

Radiosondes released between the equator and $5^{\circ} \mathrm{S}$ show a dry region east of the dateline in the first 2 weeks of CEPEX collocated with a clear sky region observed from the GMS satellite. Both features vanish in the second 2 weeks as the SST increases and, subsequently, the frequency of convection sharply increases. Generally, the ECHAM model reproduces both phenomena in the first half of CEPEX and the change in convective activity during the second half. However, a more detailed comparison shows considerable dislocations of convective areas or dry regions in ECHAM as compared to the observed ones.

Statistical comparison of the probability of occurrence of infrared brightness temperature (IRBT) and albedo versus SST derived from the GMS satellite during CEPEX confirms earlier results that there is a sharp increase in deep convective activity when SSTs rise from $299 \mathrm{~K}$ to $302 \mathrm{~K}$. This characteristic can be seen in ECHAM as well. Moreover, the ice water content (IWC) in convective anvils has been measured with a 2 DC probe and analyzed as a function of in-cloud temperature. ECHAM bears striking resemblance with the observations in absolute values and increase of IWC with temperature. However, due to the coarse resolution of the model grid, the variability within each temperature bin is underestimated by the model.

A comparison of the anomalies of the relative humidity profiles grouped according to SST and IRBT indicates that ECHAM on the whole captures the observed behavior. When convection takes place and the SST is above $301.5 \mathrm{~K}$, the atmosphere is moister than on average, in particular at higher 


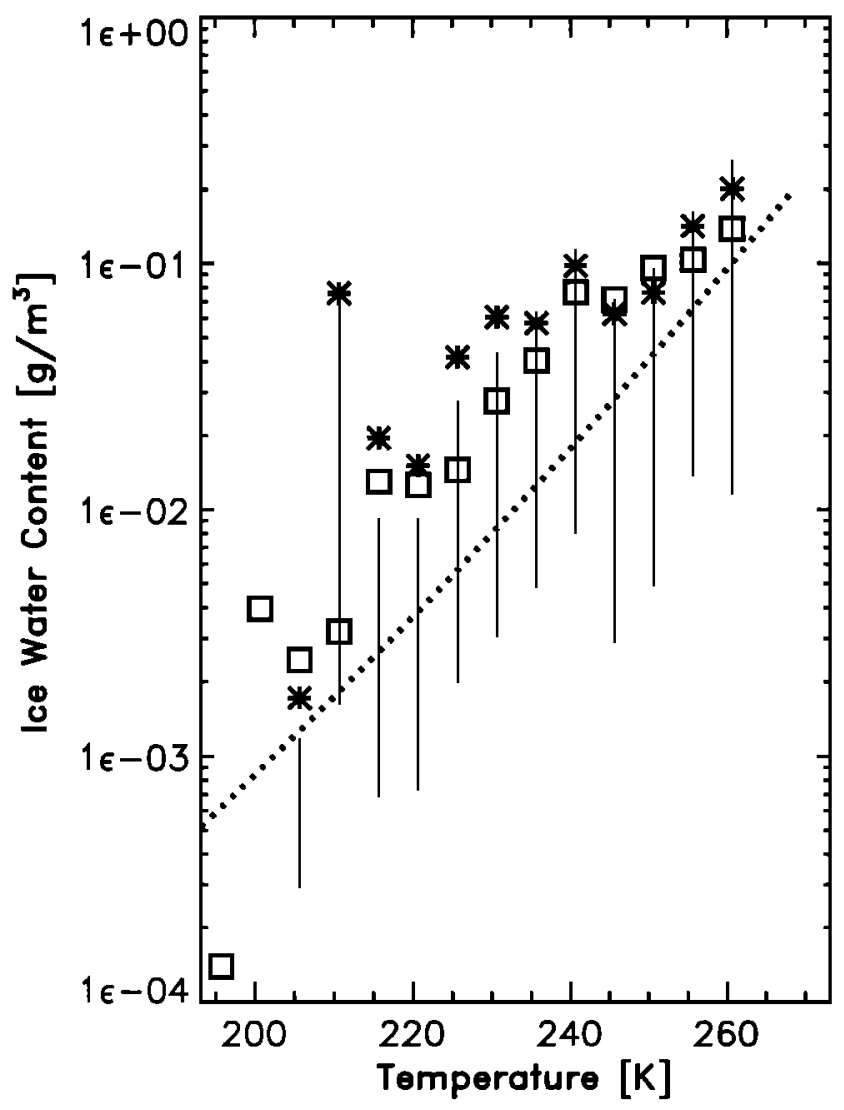

Figure 16. Average ice water content versus in-cloud temperature in $5 \mathrm{~K}$ temperature bins from $2 \mathrm{DC}$ probe data carried on the Aeromet Learjet (stars) and ECHAM4 (squares). Additionally, another relationship derived from a tropical dataset taken at the Kwajalein [Heymsfield, 1993] is indicated as dotted line. Vertical bars represent the $25 \%$ and $75 \%$ quartiles from the Learjet data.

altitudes, while the atmosphere is dryer than on average for the opposite case. Although the magnitude of the simulated relative humidity anomalies is underestimated, the link between water vapor, convection, and SST is clearly simulated. However, in ECHAM a dry bias in the lower and midtroposphere and a wet bias above $300 \mathrm{hPa}$ is obvious.

These somewhat distorted relative humidity profiles below $300 \mathrm{hPa}$, especially in areas with deep convective clouds, are possibly related to a deficient convective moisture transport [cf. Norquist and Chang, 1994]. Although the present cumulus parameterization scheme [Nordeng, 1994] assumes organized detrainment from a spectrum of clouds at different levels, the cloud spectrum is specified in a highly idealized way and can probably not account for the full complexity of tropical cloud systems. Moreover, subgrid-scale condensation, cloud formation, and release of precipitation in convective anvils are crudely represented [Roeckner et al., 1991] and may be the source of additional errors. The velocity potentials from ECHAM and ECMWF are very similar, so that the wet bias in relative humidity above $300 \mathrm{hPa}$ cannot be attributed to deficiencies in the general circulation during CEPEX. Sensitivity experiments have shown that it is possible to eliminate this bias when large-scale clouds are allowed to form at lower relative humidities. Further experiments are planned to isolate the contribution of the individual processes.

Acknowledgments. This research was supported by grants EV5V-CT92-0122 (U. Lohmann and E. Roeckner), NSF ATM-8920119 and NSF ATM-94-05024 (W. D. Collins, A. J. Heymsfield, and G. M. McFarquhar) and DE-FG03-91ER61198 (T. P. Bamett). Ulrike Lohmann would like to thank the Center for Clouds, Chemistry and Climate (C4) at the Scripps Institute of Oceanography for its hospitality during the time of this study. We acknowledge ECMWF for providing the analyses data. We would like to thank V. Ramanathan and Steve Sherwood, for useful discussions. Relative humidity data were kindly provided by Hartmut Grassl, Sam Oltmans, Steve Sherwood, and Steve Williams. Finally, we would like to thanks the anonymous reviewers for helpful comments and suggestions. This is report 146 from the Center for Clouds, Chemistry and Climate.

\section{References}

Bauer, P., and P. Schlüssel, Rainfall, total water, ice water, and water vapor over sea from polarized microwave simulations and Special Sensor Microwave / Imager data, J. Geophys. Res., 98, 20,737-20,759, 1993.

Brinkop, S., and E. Roeckner, Sensitivity of a general circulation model to parameterizations of cloud-turbulence interactions in the atmospheric boundary layer, Tellus 47A, 197-220, 1995.

Central Equatorial Pacific Experiment (CEPEX) Experiment Design, 54pp., Scripps Institution of Oceanography, 1993.

Central Equatorial Pacific Experiment (CEPEX) Operations Summary, 321pp., UCAR Off. of Field Proj. Supp., prepared by S. F. Williams, 1993.

Cess, R. D., et al., Intercomparison and interpretation of climate feedback processes in 19 atmospheric general circulation models, J. Geophys. Res., 95, 16,601-16,615, 1990.

Chahine, M. T., The hydrological cycle and its influences on climate, Nature, 359, 373-380, 1992.

Chen, C. T., and E. Roeckner, Validation of the Earth radiation budget as simulated by the Max Planck Institute for Meteorology general circulation model ECHAM4 using satellite observations of the Earth Radiation Budget Experiment (ERBE), Max Planck Inst. Meteorol. Rep. 166, 56pp., Hamburg, Germany, 1995.

Chen, C. T., E. Roeckner, and B. J. Soden, A comparison of satellite observations and model simulations of column integrated moisture and upper tropospheric humidity, Max Planck Inst. Meteorol. Rep. 155, 48pp., Hamburg, Germany, 1995.

Claussen, M., U. Lohmann, E. Roeckner, and U. Schulzweida, A global data set of land-surface parameters, Max Planck Inst. Meteorol. Rep. 135, 23pp., Hamburg, Germany, 1994.

Collins, W. D., D. Lubin, P. Flatau, B. Subasilar, and C. P. Weaver, Determination of surface heating by cirrus clouds in the equatorial Pacific, Eos Trans. AGU, 74(43), Fall Meet. suppl., 115, 1993.

Collins, W. D., W. C. Conant, and V. Ramanathan, Earth radiation budget, clouds, and climate sensitivity, pp. 207-215, in The Chemistry of the Atmosphere: Its Impact on Global Change edited by J. G. Calvert., Oxford, England, 1994.

Emanuel, K. A., Atmospheric Convection, 580 pp., Oxford University Press, New York, 1994.

Fouquart, Y., and B. Bonnel, Computations of solar heating of the Earth's atmosphere: A new parameterization, Beitr. Phys. Atmos., 53, 35-62, 1980.

Gates, W. L., AMIP: The atmospheric model intercomparison project, Bull. Am. Meteorol. Soc., 73, 1962-1970, 1992.

Graham, N. E., and T. P. Bamett, Sea surface temperature, surface wind divergence, and convection over tropical oceans, Science, $238,657-659,1987$. 
Heckley, W. A., The performance and systematic errors of the ECMWF tropical forecasts, ECMWF Tech. Rep. 53, Euro. Cent. for Medium Range Weather Forecasts, Reading, England, 1985.

Heymsfield, A. J., Microphysical structures of stratiform and cirrus clouds, in Aerosol-Cloud-Climate Interactions, edited by P. V. Hobbs, pp. 97-121, Academic, San Diego, Calif., 1993.

Illari, L., The quality of satellite precipitable water content data and their impact on analyzed moisture fields, Tellus, 41A, 319-337, 1989.

Inamdar, A. K., and V. Ramanathan, Physics of greenhouse effect and convection in warm oceans, J. Clim., 7, 715-731, 1994.

Kley, D. H., H. Voemel, H. Grassl, V. Ramanathan, S. Sherwood, and S. F. Williams, Cross section of tropospheric water vapor during CEPEX between 160 degrees east and 160 degrees west, Eos Trans. $A G U, 74(43)$, Fall Meet. suppl., 115, 1993.

Liou, K. N., Influence of cirrus clouds on weather and climate processes: A global perspective, Mon. Weather Rev., 114, 1167 $1199,1986$.

Liu, T. W., W. Tang, and F. Wentz, Precipitable water and surface humidity over global oceans for the SSM/I and ECMWF, J. Geophys. Res., 97, 2251-2264, 1992.

Matveev, L. Y., Cloud Dynamics, 340 pp., D. Reidel, Norwell, Mass., 1984.

Morcrette, J.J., Description of the radiative scheme in the ECMWF model, Tech. Rep. 165, 26pp., Euro. Cent. for Medium Range Weather Forecasts, Reading, England, 1989.

Nordeng, T. E., Extended versions of the convective parameterization scheme at ECMWF and their impact on the mean and transient activity of the model in the tropics, Tech. Memo. 206, 41pp., Euro. Cent. for Medium Range Weather Forecasts, Reading, England, 1994.

Norquist, D. C., and S. S. Chang, Diagnosis and correction of systematic humidity error in a global numerical weather prediction model, Mon. Weather Rev., 122, 2442-2460, 1994.

Ramanathan, V., and W. Collins, Thermodynamic regulation of ocean warming by cirrus clouds deduced from the 1987 El Nino, Nature, 351, 27-32, 1991.

Rasch, P. J., and D. L. Williamson, Computational aspects of moisture transport in global models of the atmosphere, Q.J.R. Meteorol. Soc., 116, 1071-1090, 1990.

Rockel, B., E. Raschke, and B. Weyres, A parameterization of broad band radiative transfer properties of water, ice and mixed clouds, Beitr. Phys. Atmos., 64, 1-12, 1991.

Roeckner, E., M. Rieland, and E. Keup, Modelling of clouds and radiation in the ECHAM model, ECMWF/WCRP Workshop on "Clouds, radiative transfer and the hydrological cycle", Nov. 12-15, 1990, pp. 199-222, Euro. Cent. for Medium Range Weather Forecasts, Reading, England, 1991.
Roeckner, E., et al., Simulation of the present-day climate with the ECHAM model: Impact of model physics and resolution, Max Planck Inst. Meteorol. Rep. 93, 171 pp., Germany, 1992.

Soden, B. J., and F. P. Bretherton, Evaluation of water vapor distribution in general circulation models using satellite observations, J. Geophys. Res., 99, 1187-1210, 1994.

Sundqvist, H., A parameterization scheme for non-convective con. densation including prediction of cloud water content, $Q . J . R$. Meteorol. Soc., 104, 677-690, 1978.

Tiedtke, M., A comprehensive mass flux scheme for cumulus parameterization in large-scale models, Mon. Weather Rev., 121, 3040-3061, 1989.

Waliser, D. E., and N. E. Graham, Convective cloud systems and warm-pool sea surface temperatures: Coupled interactions and self-regulation, J. Geophys. Res., 98, 12,881-12,893, 1993.

Waliser, D. E., N. E. Graham, and C. Cautier, Comparison of the highly reflective cloud and outgoing longwave radiation datasets for use in estimating tropical deep convection, J. Clim., 6, 331$353,1993$.

Weaver, C. P., W. D. Collins, and H. Graßl, The relationship between clear-sky atmospheric greenhouse effect and deep convection during the Central Equatorial Pacific Experiment (CEPEX): Model calculations and satellite observations, J. Geophys. Res., 99, 25,891-25,901, 1994.

Zhang, C., Large-scale variability of atmospheric deep convection in relation to sea surface temperature in the tropics, J. Clim., 6, 1898-1913, 1993.

Zhang, G. J., S. Sherwood, T.P. Barnett, and V. Ramanathan, Comparison between general circulation model simulation and Central Equatorial Pacific Experiment measurements, Proc. 4th Atmos. Rad. Meas. (ARM) Science Team Meeting, Charleston, South Carolina, 361-365, 1994.

T. P. Bamett, Scripps Institution of Oceanography, La Jolla, CA 92093. (e-mail: tbamett@ucsd.edu).

W. D. Collins, Center for Clouds, Chemistry and Climate, Scripps Institution of Oceanography, La Jolla, CA 92093. (e-mail: bill@fiji.ucsd.edu).

A. J. Heymsfield and G. M. McFarquhar, National Center for Atmospheric Research, Boulder, CO 80307. (e-mail: heyms@ash.mmm.ucar.edu; mcfarq@ncar.ucar.edu).

U. Lohmann and E. Roeckner, Max Planck Institute for Meteorology, Bundesstr. 55, 20146 Hamburg, Germany. (e-mail: lohmann@dkrz.de; roeckner@dkrz.de).

(Received March 16, 1995; revised September 1, 1995; accepted September 1, 1995.) 